\title{
Review Article \\ Carbon Nanotubes: An Emerging Drug Carrier for Targeting Cancer Cells
}

\author{
Vaibhav Rastogi, ${ }_{1}^{1}$ Pragya Yadav, ${ }^{1}$ Shiv Sankar Bhattacharya, ${ }^{1}$ Arun Kumar Mishra, \\ Navneet Verma, ${ }^{1}$ Anurag Verma, ${ }^{1}$ and Jayanta Kumar Pandit ${ }^{2}$ \\ ${ }^{1}$ School of Pharmaceutical Sciences, IFTM University, Moradabad, Uttar Pradesh 244001, India \\ ${ }^{2}$ Department of Pharmaceutics, Institute of Technology, Banaras Hindu University, Varanasi, Uttar Pradesh 221005, India
}

Correspondence should be addressed to Vaibhav Rastogi; vaib.asa@gmail.com

Received 23 October 2013; Revised 26 January 2014; Accepted 12 March 2014; Published 24 April 2014

Academic Editor: Hans E. Junginger

Copyright (C) 2014 Vaibhav Rastogi et al. This is an open access article distributed under the Creative Commons Attribution License, which permits unrestricted use, distribution, and reproduction in any medium, provided the original work is properly cited.

During recent years carbon nanotubes (CNTs) have been attracted by many researchers as a drug delivery carrier. CNTs are the third allotropic form of carbon-fullerenes which were rolled into cylindrical tubes. To be integrated into the biological systems, CNTs can be chemically modified or functionalised with therapeutically active molecules by forming stable covalent bonds or supramolecular assemblies based on noncovalent interactions. Owing to their high carrying capacity, biocompatibility, and specificity to cells, various cancer cells have been explored with CNTs for evaluation of pharmacokinetic parameters, cell viability, cytotoxicty, and drug delivery in tumor cells. This review attempts to highlight all aspects of CNTs which render them as an effective anticancer drug carrier and imaging agent. Also the potential application of CNT in targeting metastatic cancer cells by entrapping biomolecules and anticancer drugs has been covered in this review.

\section{Introduction}

After the discovery of the third allotropic form of carbon fullerene in 1991, Sumio Iijima identified a new structural form of this allotrope, the cylindrical fullerene and named them as carbon nanotubes (CNTs) [1]. CNTs are graphene sheets rolled into a seamless cylinder that can be open ended or capped, having a high aspect ratio with diameters as small as $1 \mathrm{~nm}$ and a length of several micrometers [2]. Depending on the number of sheets rolled into concentric cylinders, there are two broad categories of CNTs, namely, single-walled carbon nanotubes (SWCNTs) and multiwalled carbon nanotubes (MWCNTs) (Figure 1). SWCNTs are made up of single graphene layer wrapped into a hexagonal closepacked cylindrical structure whose diameter varies from 0.4 to $3.0 \mathrm{~nm}$ and length ranges from 20 to $1000 \mathrm{~nm}$ and are held together by Vander Waals forces, which makes them easily twistable and more pliable [3]. SWCNTs are produced by the electric arc [4], laser ablation [5], chemical vapor deposition (CVD) [6], and gas-phase catalytic processes (HiPco or high-pressure CO conversion) [7].
MWCNTs consist of several coaxial cylinders, each made of a single graphene sheet surrounding a hollow core. The outer diameter of MWCNTs ranges from 2 to $100 \mathrm{~nm}$, while the inner diameter is in the range of $1-3 \mathrm{~nm}$, and their length is 1 to several $\mu \mathrm{m}$ [8]. Electric arc [9] and chemical vapor deposition (CVD) $[10,11]$ are the main techniques for their production. Owing to the $\mathrm{sp}^{2}$ hybridization in MWCNTs, a delocalized electron cloud along the wall is generated which is responsible for the $\pi-\pi$ interactions between adjacent cylindrical layers in MWCNTs resulting in a less flexible and more structural defects [12].

With more than 10 million new cases every year, cancer is one of the most devastating diseases. Though the current treatments of cancer by surgery, radiation, and chemotherapy are successful in several cases; however, these curative methods are likely to kill healthy cells and cause toxicity to the patient [13]. Many patients who succumb to death due to cancer do not die as a result of the primary tumor, but because of the systematic effects of metastases on the other regions away from the original site. One of the aims of cancer therapy is to prevent the metastatic process as early as 


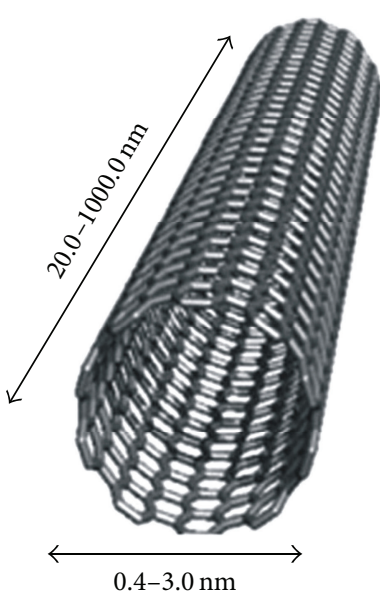

(a)

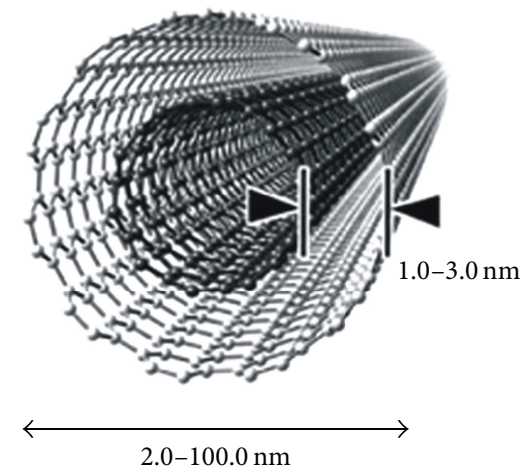

(b)

FIGURE 1: Carbon nanotube: (a) single walled carbon nanotube and (b) multiwalled carbon nanotube.

possible. Therefore, significant amounts of research have been carried out to overcome these problems. The main problem incurred with various chemotherapies for treating cancer is lack of selectivity of the anticancer drug towards cancerous cells. This nonspecificity of the drug limits the therapeutic dose within cancer cells while providing excessive toxicities to normal cells, tissues, and organs and thereby causing several adverse effects. Besides precise tumor targeting and toxicity concerns, drug resistance remains a major obstacle for the treatment of advanced cancerous tumor [14-16]. "Cancer nanotechnology" is the novel emerging field which used nanocarriers like liposome, polymeric nanoparticles, dendrimers, quantum dots, polymersomes, carbon nanotubes, and so forth, for delivering drugs to the target site and thus holds tremendous potential to overcome several problems associated with the conventional therapies [17, 18]. Apart from the several advantages of these nanocarriers, some of them pose challenges of their own. For instance, liposomes have been used as a potential carrier with unique advantages, including protecting drugs from degradation, reduction in toxicity, or side effects, but the applications of liposomes were found to be limited due to the inherent problems such as low encapsulation efficiency, poor solubility of many drugs in the lipid/surfactant solution and rapid leakage of water soluble drug in the presence of blood components as well as unpredictable storage stability [19]. Since precise tumor targeting with reduction in toxicity is the chief objective in cancer therapy, some nanocarriers like immunoliposomes (a class of liposomes) exhibit their inability to actively target the specific cells because the ligands conjugated with liposomes may increase the liposome size and reduce extravasation which may tend to be rapidly cleared by the cells of reticuloendothelial system (RES) [20]. Similarly, targeted nanoparticles (NPs) also faced many challenges. One challenge faced by targeting NPs is that NPs might change the stability, solubility, and pharmacokinetic properties of the carried drugs while another challenge is associated with the shelf life, aggregation, leakage, and toxicity of materials used to make NPs, for example, poly (lactic-co-glycolic acid) (PLGA), a polymer of choice nowadays among the researchers to fabricate NPs because of their low toxicity and high targeting efficiency, but they degrade quickly and do not circulate in tissues long enough for sustained drug/gene delivery which limits their usability in long term cancer therapy. On the other hand, CNTs can persist in the body for weeks, months, or even years, thus limiting their use for repeated treatments $[15,21]$. If we talk about dendrimers, they are synthetic, branched macromolecules that form a treelike structure whose synthesis represents a relatively new field in polymer chemistry. Though promising, dendrimers are more expensive than other nanocarriers like CNTs and require many repetitive steps for synthesis, posing a challenge for large-scale production [22]. In the recent years of research, reported data clearly reveals that CNTs have an enormous potential and possess high entrapment efficiency to carry the therapeutic molecule as earliest to the site of cancer cell without activating the immune system and damage to other viable cells although toxicity issues related to CNTs are under research. This review highlights the insights of the CNTs and their potency in delivering the anticancer drugs to combat various metastatic cancer cells specifically.

\section{Production of CNTs}

The production of CNTs complies with the transformation of a carbon source into nanotubes, usually at high temperature and low pressure, wherein the synthesis conditions influence the characteristics of the final product. Since prepared CNTs are usually associated with carbonaceous or metallic impurities, therefore, purification is an essential step to be considered [23]. Methods of CNTs purification include chemical methods, particularly oxidation (gas phase [24], liquid phase [25]), physical methods (filtration [26], centrifugation [27], and high temperature annealing [28], etc.), and multistep purification [29]. 


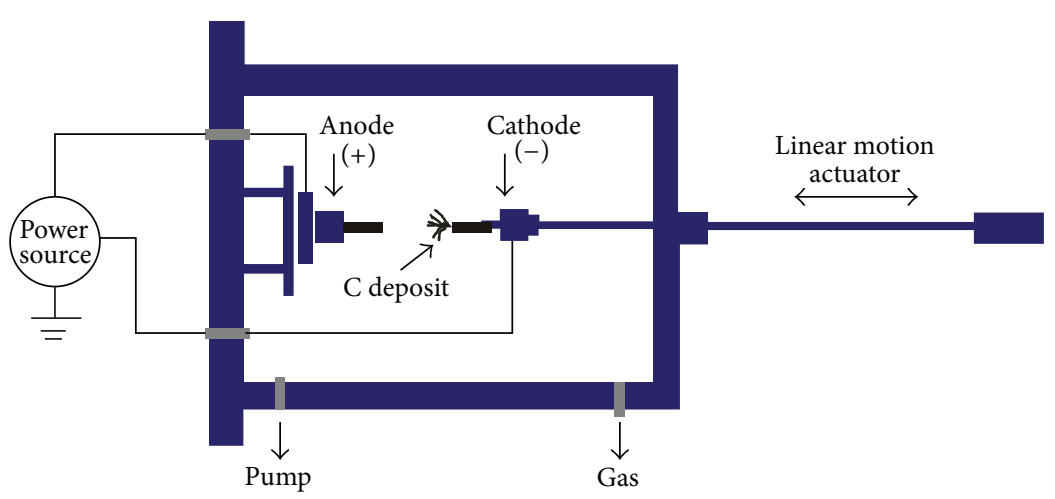

(a)

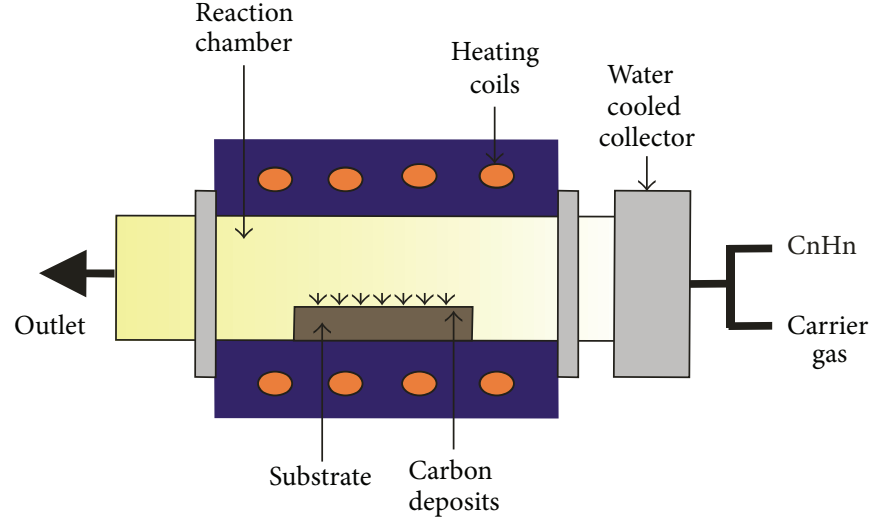

(b)

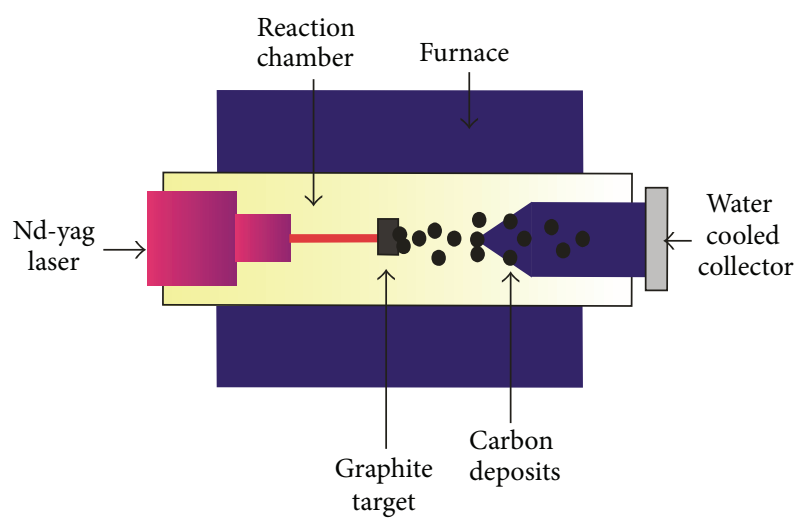

(c)

FIGURE 2: Schematic representation of methods used for carbon nanotube synthesis: (a) Arc discharge method, (b) chemical vapour deposition method, (c) laser ablation method.

Presently, there are three main approaches for the synthesis of CNTs (Figures 2 and 3 ) including electric arc discharge, the laser ablation and the chemical vapor deposition (CVD).

2.1. Arc Discharge Method. This method is the oldest method used by Iijima in 1991 when CNTs were first identified [1]. Figures 2(a) and 3(a) showed the synthesis of CNTs by arc discharge method. In this method, an arc is generated, when a DC current of $200 \mathrm{~A}$ to $20 \mathrm{~V}$ is applied across two carbon electrodes which are placed in a vacuum chamber that is typically filled with inert gas (Helium, argon) at low pressure ( $\sim 50 \sim 700 \mathrm{mbar})$. The positive electrode is gradually brought closer to the negative one to strike the electric arc. The electrodes become red hot and such an extreme condition turns the gas into plasma, a fluid of negatively and positively charged particles generating a temperature high enough to vaporize materials. Once the arc stabilizes, the electrodes are kept about a millimetre apart while the CNT deposits on the negative electrode $[30,31]$. The two most important parameters to be taken care of in this method are (1) the control of arcing current and (2) the optimal selection of inert gas pressure in the chamber.

Ebbesen and Ajayan [9], for the first time, reported synthesis of CNTs on a large scale and optimized the yield of nanotubes by varying conditions such as type of inert gas, pressure, the nature of current (A.C. or D.C.), the voltage, and the relative rod size. They showed the optimal yield of CNTs at 500 torr pressure. In another study, Ohkohchi et al. studied the growth promoting effect of scandium on nanotubes by using a carbon composite rod containing scandium oxide for the synthesis of CNTs by arc discharge evaporation [32]. Lee et al. and Antisari et al. reported high yield of MWCNTs by electric arc discharge in liquid environments, particularly in liquid nitrogen and deionised water [33,34]. Alternatively, Wang et al. used sodium chloride solution as a liquid medium because of its significant cooling ability and excellent electrical conductivity than deionised water and concluded successful synthesis of MWCNTs with the formation of a single sheet of SWCNT [35]. Anazawa et al. demonstrated the introduction of magnetic field in arc discharge synthesis to obtain high-purity/defect-free (purity > 95\%) MWCNTs [36]. Ando et al. modified this method by a newly developed DC arc plasma jet method for the evaporation of metal doped carbon anode. They showed a high production rate $(1.24 \mathrm{~g} / \mathrm{min})$ as compared to the conventional method [37]. Cheng et al. devised a hydrogen arc discharge method for the production of SWCNTs with high hydrogen capacity using graphite powder, catalyst metal, and a growth promoter in an atmosphere containing hydrogen [38].

The diameter and the linearity of the SWCNTs can be controlled by the modification in the synthesis procedure. In a study, Farhat et al. altered the inert gas nature by increasing 


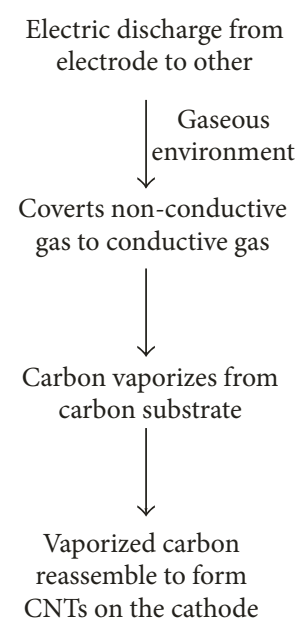

(a)

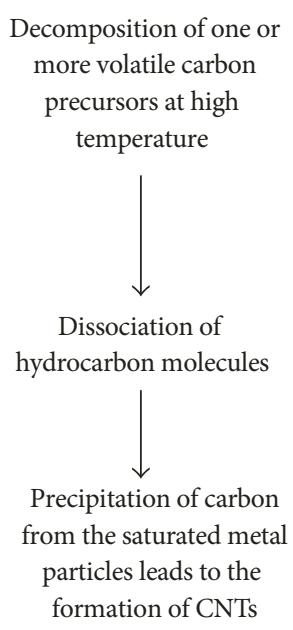

(b)

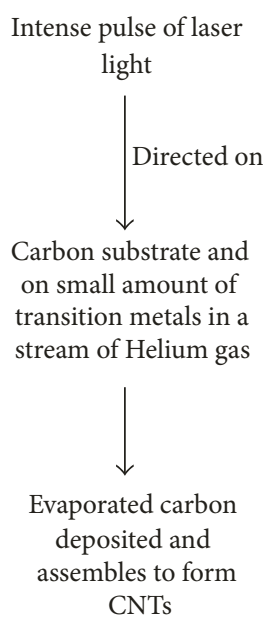

(c)

Figure 3: Mechanism of carbon nanotube synthesis: (a) Arc discharge method, (b) chemical vapor deposition method, and (c) laser ablation method.

the argon fraction in the inert gas mixture which resulted in the decrease in nanotube diameter [39].

Further, Kajiura et al. also synthesized SWCNTs with narrow diameter distributions using a DC arc discharge method with bimetallic combination (Yttrium-Nickel alloy) as a catalyst and Selenium as parameter [40]. They showed that SWCNTs obtained by this method can be readily purified up to $>99 \%$ with traditional purification as compared with the above study by Farhat et al.

Among several methods for preparing CNTs, arc discharge is the most practical and inexpensive approach for scientific purposes because the method yields highly graphitized tubes due to high process temperature. However, despite of the above fact, this method produces many byproducts besides CNTs. As a result, the process requires well-controlled purification steps to maintain the quality of nanotubes and eliminate species such as amorphous carbon and metallic nanoparticles [41]. Furthermore, due to the relatively little control over the alignment (i.e., chirality) of the produced nanotubes, the characterization becomes complex.

2.2. Chemical Vapour Deposition (CVD). While the arc discharge method is capable of producing large quantities of unpurified nanotubes, significant effort is being directed towards production processes that offer more controllable routes to the nanotube synthesis. One of the such process is chemical vapour deposition (CVD) that seems to offer the best chance to obtain a controllable process for the selective production of nanotubes with predefined properties [42]. Apart from materials scale-up, controlled synthesis of aligned and ordered CNTs can be achieved by using CVD [43]. The microstructure of the CNT tips synthesized by the CVD technique exhibits well-formed caps compared to other techniques. Therefore CVD is the preferred method for production of CNTs over other methods. The brief schematic representation of this method is given in Figures 2(b) and 3(b). In this method a mixture of hydrocarbon gas (ethylene, methane, or acetylene) and a process gas (ammonia, nitrogen, and hydrogen) is made to react in a reaction chamber on heated metal substrate at a temperature of around $700^{\circ} \mathrm{C}-$ $900^{\circ} \mathrm{C}$, at atmospheric pressures. Residual gas diffuses away, whereas free carbon atoms dissolve into the nanoparticles and then segregate to the catalyst surface to form nanotubes [44]. The key parameters include the nature of hydrocarbons, catalysts, and the growth temperature. Depending on the reaction conditions and catalyst preparations, this method may be applied to obtain either SWCNTs or MWCNTs [45].

There are two possible mechanisms for the catalyst assisted nanotube growth, namely, tip growth [46] and root growth mechanism [47]. Balbuena et al. demonstrated the role of catalyst in the growth of SWCNTs by using model Co-Mo catalyst and also studied the role of catalyst/substrate interactions [48]. They found that a strong cluster/substrate interaction increases the cluster melting point, modifying the initial stages of carbon dissolution and precipitation on the cluster surface.

In a study Hoffmann et al. reported the critical effects of $\mathrm{NH}_{3}$ or $\mathrm{H}_{2}$ on $\mathrm{Fe}$ thin film catalyst restructuring which enabled the surface bound growth of SWCNTs at temperature as low as $350^{\circ} \mathrm{C}$ by CVD [49]. They observed narrow diameter of the SWCNTs formed at low temperature. Various efforts have been taken to modify this technique. One such example is reported by Chen et al. and Choi et al. They showed that by taking advantage of low temperature with the addition of microwave energy that is, microwave plasma-enhanced CVD (PECVD), an increase was seen in the yield of vertically aligned MWCNTs being successfully synthesized [50, 51]. In another study Huisken et al. replaced the global heat source for the furnace with a localized spot heated by a laser and thus studied the suitability of laser assisted CVD (LCVD) for the formation and growth of nanotubes. In this study, they utilized medium power continuous wave $\mathrm{CO}_{2}$ laser to irradiate a sensitized mixture of $\mathrm{Fe}(\mathrm{CO})_{5}$ vapour and acetylene to heat the silicon substrate simultaneously on 
which CNTs were grown [52]. Similarly, Lackey et al. also demonstrated the use of LCVD for the synthesis of CNTs [53]. A novel continuous process registered by Khodadadi et al. involves catalytic chemical vapour deposition (CCVD) of methane on iron floating catalyst in situ deposited on $\mathrm{MgO}$ in fluidized bed reactor for the production of CNTs [54].

A major drawback associated with the CVD technique is that there are high defect densities in the MWNT structures grown by this process due to the lack of sufficient thermal energy for annealing CNTs because of relatively low growth temperature [55].

2.3. Laser Ablation Method. This method was developed by Smalley et al., in which direct laser beam was focused on transition-metal/graphite composite rods to produce SWCNTs [56]. In the laser ablation process, a pulsed laser is made to strike at a graphite target in a high temperature reactor (furnace) in the presence of inert gas such as helium which vaporizes the graphite target and forms a laser plume. The laser plume contains vaporized carbon and metallic nanoparticles that lead to the reassembling of carbon in the form of carbon nanotubes. The nanotubes develop on the cooler surfaces of the reactor, as the vaporized carbon condenses. Nanotubes produced by laser ablation have higher purity (up to about $90 \%$ pure) and their structure is better graphitized than those produced by the arc discharge method. The high cost of laser and small carbon deposit are the major limitations of this method. In addition to this, the method mainly favors the growth of SWCNTs and special reaction conditions are required to generate MWCNTs [57].

Several researchers reported different modifications of the laser ablation method to improve the geometry and yield of SWCNTs (Figures 2(c) and 3(c)). In a study, Maser et al. used continuous wave $250 \mathrm{~W} \mathrm{CO}_{2}$ laser operating at $10.6 \mu \mathrm{m}$ wavelength to evaporate graphite/bimetal targets and produced high densities bundles of SWCNTs [58] while Yudasaka et al. showed an improved yield of SWCNTs by pulsed laser over a continuous one [59]. Zhang et al. studied the effect of laser frequency and laser power (or temperature) on the diameter distribution of SWCNTs [60].

Scott et al. demonstrated the growth mechanism for SWCNTs in a laser ablation process. They suggested that in addition to the carbon obtained from direct ablation of the target, other substances like carbon particle suspended in the reaction zone, $\mathrm{C}_{2}$ obtained from photodissociation of fullerenes, and other low molecular weight species may also serve as feedstock for nanotube growth [61].

Maser et al. reported that, similar to the arc discharge method, pressure and composition of the inert gas play a significant role in laser ablation synthesis and affect the yield and structural properties of CNTs. Both argon and nitrogen at a pressure between 200 and 400 torr resulted in higher yield of SWCNTs [62]. Apart from this factor another important factor is the carbon source used. Vander Wal et al., in their study, replaced the conventional laser-ablation-furnace approach with the laser ablation in the flame environment. The main advantage of this modification is that it gives an energy efficient approach since a portion of the fuel is burned to create the elevated temperature while the remainder of the fuel and its incomplete combustion byproducts can serve as the reactive carbon source for nanotube synthesis [63].

Thus, both arc discharge method and laser ablation method can be used to produce high quality CNTs. However, efforts to scale up the process are needed to achieve synthesis of larger quantities with maximum purity.

\section{Functionalization}

Despite of the advantages of CNTs in targeting various types of cancer cells, various constraints have been made on the biological and biomedical applications of CNTs due to their lack of solubility in aqueous medium as well as their toxicity caused by the hydrophobic surface. These limitations of CNTs can be overcome by a process called Functionalization [64]. CNT without surface modification, are cytotoxic to certain mammalian cells, for example, pure MWCNTs can injure plasma membrane of human macrophages. Therefore, strategies for surface functionalization including covalent and noncovalent functionalization are carried out on the synthesized CNTs [65]. The process of functionalization is also helpful in conjugating the therapeutic molecule or the ligands to the CNTs either on the surface or on the ends of CNTs to render them active against cancer cells. In this context, recently, a novel immunologically modified nanotube system was invented by Chen using glycated chitosan (GC), a potent immunoadjuvant, as an effective surfactant for single-walled carbon nanotubes (SWCNTs). Upon laser irradiation of target tumor cells, administration of SWCNTGC resulted in highly effective tumor suppression in animal tumor models, with complete tumor regression and longterm survival in many cases [66]. In a study Dai et al. used oxidised CNT to covalently link fluorescein or biotin (ligand), allowing the formation of biotin-avidin complex with fluorescent streptavidin for observing the penetration pathway of protein-CNT conjugates in the cell [67].

In order to get validated with the modified CNT through functionalization, characterization with respect to pristine CNT is necessary to conduct and to ascertain that the developed CNTs possess altered characteristics with respect to functionalization. There are several analytical techniques which are used in the chemical and structural characterization of modified CNTs [68]. IR spectroscopy (functional group identification) $[69,70]$, X-ray photoelectron microscopy (degree of functionalization) [70,71], electron microscopy (structural characterization) [69], BrunauerEmmett-Teller (BET) analysis (surface area measurement) [72], chemical derivatization (quantification of targeted functional group) [73], thermogravimetric analysis (thermal stability and purity evaluation) [74, 75], and Raman spectroscopy (for ascertaining purity, defects, tube alignment, and structural properties) $[76,77]$ are some reported techniques used for characterization of CNTs after functionalization.

Schematic representation of functionalized CNTs with various molecules is given in Figure 4. The functionalization can be divided into two main subcategories: noncovalent functionalization and covalent functionalization. 


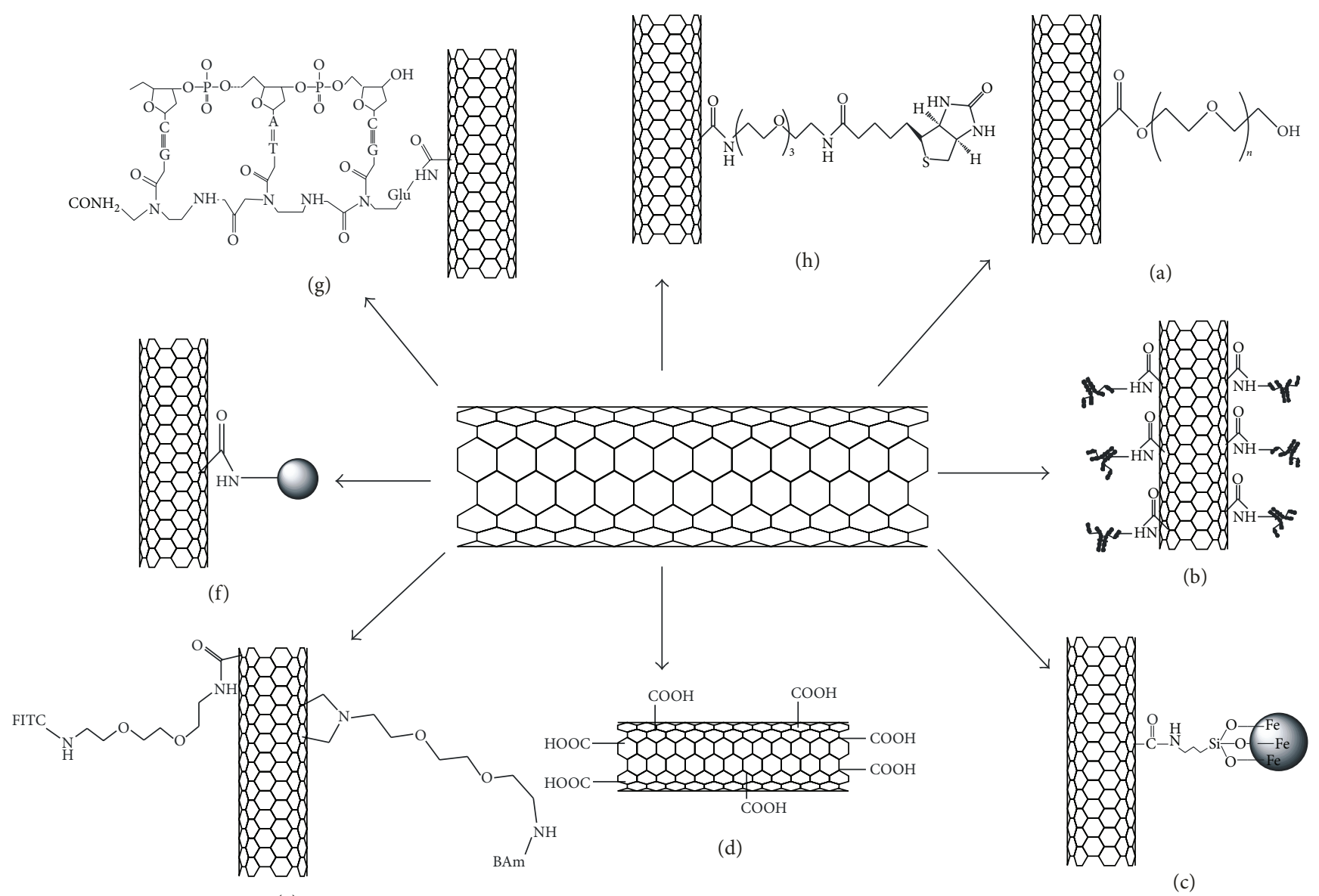

(e)

FIgURE 4: Schematic illustration of functionalization of CNTs with various molecules: (a) Prakash et al. [18], (b) Xiao et al. [78], (c) Xu et al. [70], (d) Gomez-Gualdron et al. [64], (e) Bianco et al. [79], (f) Jiang et al. [80], (g) Williams et al. [81], and (h) Kam and Dai [82].

3.1. Covalent Functionalization. Covalent functionalization of CNTs with the therapeutically active molecule or the biocompatible surfactants is governed by the oxidation of CNTs using strong acids (conc. $\mathrm{H}_{2} \mathrm{SO}_{4}$ or conc. $\mathrm{HNO}_{3}$ ) which generates substitutable hydrophilic functional groups such as $\mathrm{COOH}$ and $\mathrm{OH}$ on the CNTs which then further undergo into the chemical reactions such as esterification, amidation, chlorination, bromination, hydrogenation, and Diel's-Alder reaction. In order to get functionalized with these active molecules, CNTs allow side-wall covalent attachment of functional groups by the addition of radicals, nucleophilic carbenes, nitrenes, nucleophilic cyclopropanation, and electrophiles $[79,83,84]$. The method of oxidation results in the opening of the CNT end caps, generating carboxylic groups suitable for enhancing the solubility of the CNTs with improved biocompatibility [85]. It has been shown that a highly negative charge developed as a result of the carboxylation increases the hydrophilicity of CNTs. Covalent linkage of polyethylene glycols increases the hydrophilicity and the solubility of CNTs in aqueous media as well as increasing the size which reduces the rate of clearance of CNTs through the kidneys and tends to increase the circulation time in the plasma. Tour et al. proposed the functionalization of CNTs in acidic media, which yields oxidized CNTs in large and industrial scale quantities [86]. Side wall functionalization of SWCNTs through C-N bond forming substitutions of fluoronanotubes was explored by Khabashesku et al. and reported that this method offers a wide range of further SWCNTs derivatizations including their covalent binding to amino acids, DNA, and polymer matrix [87].

3.2. Noncovalent Functionalization. Noncovalent functionalization involves Van der Waals interactions, $\pi-\pi$ interactions, and hydrophobic interactions of biocompatible functional groups with the surface of the CNT. One of the main advantages of this type of bonding is the minimal damage caused to the CNT surface. It has been suggested that noncovalent attachment preserves the aromatic structure and thus the electronic character as compared to pristine CNTs. This type of functionalization can be done by the addition of hydrophilic polymers, biopolymers, and surfactants to the walls of CNTs through weak bonds [88].

A series of anionic, cationic, and nonionic surfactants have been already proposed to disperse nanotubes in aqueous media. Sodium dodecyl sulfate (SDS) and benzylalkonium chloride are other good examples of surfactants that noncovalently aggregated to the nanotube side walls and facilitate the dissolution of CNTs in water. The adhesion between 
surfactants and nanotube walls becomes very strong due to the $\pi-\pi$ stacking interactions resulted from the attachment of aromatic groups of the amphiphile surfactant in the aromatic network of the nanotube side walls, as evidenced in the case of adhesion of N-succinimidyl-1-pyrenebutanoate [89].

In the solubilization of the CNT, polymers represent a good alternative to surfactants although they do not have a better dispersion efficiency [90]. Amphiphilic polymers or soluble polymers are often used to solubilize CNTs. The main advantage of using polymers instead of small molecular surfactants is that the polymers reduce the entropic penalty of micelle formation. Also, some conjugated polymers have significantly higher energy of interaction with nanotubes than small molecules with nanotubes [91]. In this context, hydrophilic polymer wraps around the tubes and thus modifies the solubility and conductivity properties of the CNTs. For example, polyvinylpyrrolidone (PVP), having polar sides along its long chain, assists the dissolution of PVP/SWCNT aggregates in polar solvents. Similarly Star et al. have substituted poly(metaphenylenevinylene) to suspend SWCNT in organic solvents [92]. Biopolymers can also be used for the functionalization of CNTs. Nucleic acids are certainly ideal candidates to form supramolecular complexes based on $\pi-\pi$ stacking between the aromatic bases and the CNT surface. Zhao et al. reported the DNA adsorption on a single-walled carbon nanotube (SWCNT) in an aqueous environment. The hydrophobic end groups of DNA are attracted to the hydrophobic SWCNT surface of uncharged SWCNTs, while the hydrophilic backbone of DNA does not bind to the uncharged SWCNT [93]. Jiang et al. immobilized biomolecule, bovine serum albumin (BSA) protein via two-step process of diimide-activated amidation on MWCTs. First, carboxylated MWCNTs were activated by Nethyl- $\mathrm{N}^{\prime}$-(3-dimethylaminopropyl) carbodiimide hydrochloride (EDAC), forming a stable active ester in the presence of N-hydroxysuccinimide (NHS). Second, the active ester was reacted with the amine groups on the BSA, forming an amide bond between the MWNTs and proteins. This two-step process avoids the intermolecular conjugation of proteins and guarantees the uniform attachment of proteins on carbon nanotubes [80]. William et al. developed a technique to couple SWCNTs covalently to peptide nucleic acid (PNA, an uncharged DNA analogue). Ultrasonically shortened SWCNT ropes were prepared in a 3:1 mixture of concentrated $\mathrm{H}_{2} \mathrm{SO}_{4}$ and $\mathrm{HNO}_{3}$. Subsequent exposure to $1 \mathrm{M}$ $\mathrm{HCl}$ produces abundant carboxyl end groups. This material was then dispersed in dimethyl-formamide (DMF, 99.5\%) and incubated for $30 \mathrm{~min}$ in $2 \mathrm{mM}$ 1-ethyl-3-(3-dimethylaminopropyl)carbodiimide hydrochloride and $5 \mathrm{mM} \mathrm{N}$ hydroxysuccinimide (NHS) to form SWCNT-bearing NHS esters. PNA adducts are formed by reacting this material in DMF for 1 hour with excess PNA [81].

\section{Mechanism of CNTs Penetration into the Cell}

Both types of pure CNTs, the single walled and the multiwalled carbon nanotubes have per se no affinity for cells and also no to cancer cells. That means they have to be functionalized in order to make them able to cross the membrane of the normal cells and even more specifically for targeting them to cancer cells. For this reason, they are basically similar carriers like liposomes, dendrimers, or nanoparticles. However, the advantages of SWCNTs and MWCNTs over other carriers are significant to their hexagonal close-packed cylindrical structure and $\mathrm{sp}^{2}$ hybridization which renders them to get easily functionalized with the respective ligand or therapeutic moiety. These functionalized CNTs have an ability to cross cell membranes, but the question arises as to how these functionalized CNTs can recognize their site of action and the route by which they can be delivered to the target cell. Hence, to understand the internalization process, CNTs can be tracked by labeling them with a fluorescent agent (such as fluorescein isothyocyanate) and then monitoring the uptake by using epifluorescence, confocal microscopy, and flow cytometry studies $[82,94]$. Additionally, detection of CNTs by nonlabelling methods such as transmission electron microscopy (TEM) or atomic force microscopy has also been conducted by many researchers. Kosuge et al. adopted flow cytometry and confocal microscopy to study the uptake of SWCNTs by the macrophages in murine RAW 264.7 cells. Their observation clearly showed the presence of labelled SWCNTs inside the cells [95]. Transmission electron microscopy was conducted by Bonner et al., on the murine RAW 264.7 cells for the assessment of cellular uptake and sublocalization of MWCNTs. TEM results showed that the RAW 264.7 macrophages successfully engulfed the MWCNTs [96]. Similarly, Sitharaman et al. reported the efficacy of europium $(\mathrm{Eu})$ catalyzed SWCNTs (Eu-SWCNTs), as visible nanoprobes for cellular imaging after observing the internalization of Eu-SWCNTs in the breast cancer cells (SK-BR3 and MCF-7) via cellular endocyte formation as imaged by confocal fluorescence microscopy and TEM [97].

To conclude about the exact cellular uptake pathway of CNTs is complex and it is believed that there are two possible pathways to cross the cellular membrane (Figure 5) [98]. The first is endocytosis dependent pathway which may be either receptor mediated or nonreceptor mediated and the second is based on endocytosis independent pathway which includes diffusion, membrane fusion, or direct pore transport of the extracellular material into the cell [99]. The process of internalization of CNTs depends on several parameters such as the size, length, nature of functional groups, hydrophobicity, and surface chemistry of CNTs [99, 100].

Endocytosis dependent pathway is an energy and temperature dependent transport process which involves engulfing of extracellular materials within a segment of the cell membrane to form a saccule or a vesicle (hence also called as corpuscular or vesicular transport) which is then pinched off intracellularly into the matrix/cytoplasm of the cell [101]. Furthermore, internalization endocyte formation was shown to be clathrin mediated, caveolin-driven endocytosis, and through macropinocytosis [99]. In case of receptor mediated endocytosis (Figure 5(b)), ligand conjugated-drug loaded CNT binds to the complementary transmembrane receptor 


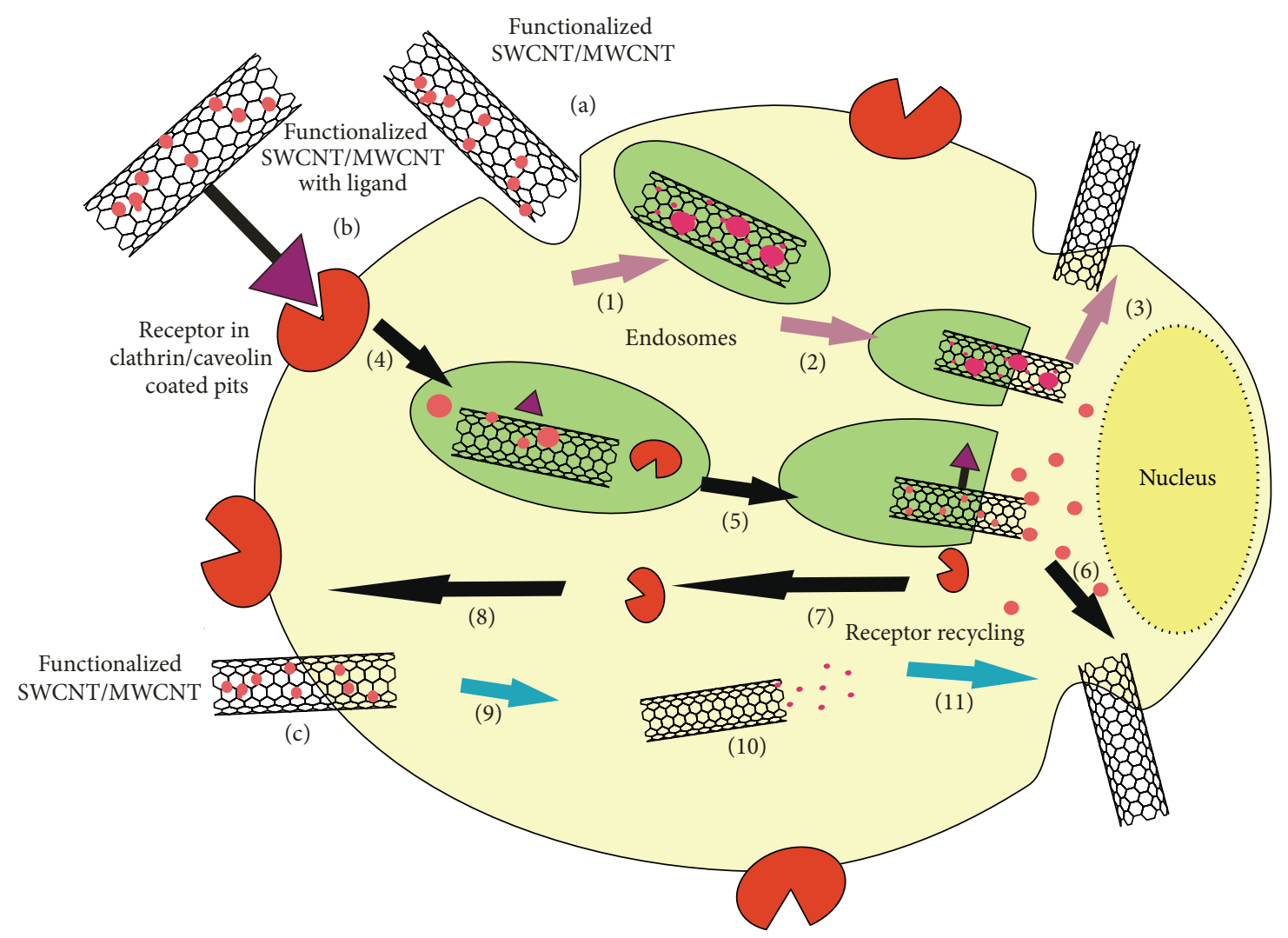

FIGURE 5: Pathways for the penetration of CNTs into the cell. (a) Nonreceptor mediated endocytosis: (1) membrane that surrounds the drug loaded functionalized CNTs, (2) internalization of drug loaded CNTs, and (3) release of drug; (b) receptor mediated endocytosis: (4) membrane surrounds the CNT-receptor conjugate by forming endosomes followed by internalization, $(5)$ release of drug, and $(6,7,8)$ regeneration of receptor; (c) endocytosis independent pathway: (9) direct penetration of drug loaded functionalized CNT and (10) release of the drug.

proteins and then enters the cell as receptor-ligand complexes in clathrin coated vesicles. After internalization vesicles are formed which were known as early endosomes and due to drop in $\mathrm{pH}$, the ligand dissociates from the receptor. When the receptors are released, the vesicles carrying the extracellular particle fuses with lysosomes and thus trigger the release of the drug particle by the action lysozymes on the endosomes and simultaneously the free receptors thus formed are being recycled to the plasma membrane for conjugating with other ligand conjugated CNTs [102]. An example from the antiangiogenetic area is the targeting of integrin $\alpha_{\mathrm{v}} \beta_{3}$, which are endothelial cell receptors for extracellular matrix proteins possessing the RGD sequence (arginine-glycine-aspartic acid) and are highly expressed on neovascular endothelial cells. Conjugation of RGD peptides to nanovectors can lead to higher levels of cellular internalization and furthermore affect vascular endothelial growth factor receptor-2 (VEGFR-2) signalling due to intrinsic association with this signalling pathway, leading to downregulation of the receptor and finally to reduced angiogenesis. Another example for active targeting based on ligand-receptor interactions relevant to this area of cancer therapeutics is the interaction of folate with its receptors. Folic acid is a vitamin and necessary for the synthesis of nucleotides, the DNA building blocks. Its counterpart, the folate receptor, is significantly upregulated by a broad spectrum of human cancers, in some cases by two orders of magnitude, facilitating cellular internalization of folateconjugated nanovectors by receptor-mediated endocytosis. Folate-conjugated nanovectors loaded with anticancer drugs have shown huge potential in overcoming the problem of multidrug resistance by evading P-glycoprotein-mediated efflux, which is considered to be a common problem in cancer drug administration [103].

In a study, Jhao et al. reported the stimulation of Tolllike receptor-9 (TLR9) presented on the intracranial GL261 gliomas bearing mice by $\mathrm{CpG}$ oligodeoxynucleotide (CpG) conjugated SWCNTs and concluded that functionalized CNTs were responsible for augmenting CpG prostimulator function by facilitating its uptake through the TLR9 receptor mediated endocyte localization into the glioma cells [104]. Iancu et al. synthesized Human serum albumin (HSA) functionalized MWCNTs inside the malignant liver cells (HepG2 cells) via $60 \mathrm{KDa}$ glycoprotein (Gp60, which is known to function as albumin transcytosis in malignant cells) selective uptake of albumin bounded CNTs by forming an endocyte around it [105]. Similarly fluorescein isothyocyanate labelled lectin conjugated SWCNTs recognises $\mathrm{N}$-acetylgalactosamine containing glycoprotein in MCF-7 breast cancer cell and internalized into the cell as ligand 
mediated endocytosis [106]. Dhar et al. conjugated cisplatinplatinum (IV) prodrug to amine functionalized SWCNTs through multiple amide linkages and demonstrated its ability to target folic receptors positive (FR+) tumor cells (human choriocarcinoma cells, JAR and human nasopharyngeal carcinoma cells, KB). Results obtained from the fluorescence microscopy analysis clearly stated the applicability of the conjugated system to selectively target FR+ receptors and the internalization of the system was through the folic acid receptor mediated endocytosis [107].

In general, the long CNTs ( $>1 \mu \mathrm{m}$ in length) were taken up by the process of phagocytosis (a part of endocytosis) which was mainly conducted by the macrophages, monocytes, and neutrophils, while the shorter CNTs (length from a few to several hundred nanometers) were mainly internalized by pinocytosis [108]. It was found that altering the hydrophobicity of the CNTs by conjugating them with phospholipids significantly alters the uptake of CNTs by the cells as observed by Kapralov et al. They compared the internalization of the surfactant (phosphatidylcholines and phosphatidylglycerols) conjugated SWCNT with pristine SWCNT in the murine RAW 264.7 cells and the data obtained from flow cytometric analysis clearly states that the adsorbed phospholipids significantly enhanced the uptake of SWCNTs via phagocytosis as phospholipids are known to greatly associate with the phospholipids head group of the cellular membrane in comparison to pristine or uncoated SWCNT [109].

In case of nonreceptor mediated endocytosis (Figure 5(a)), a small portion of the plasma membrane surrounds the drug loaded CNTs and then pinches off intracellularly as an endocyte vesicle. The process is governed by the intrinsic property of the CNTs as well as functional groups present on it. The endosomes thus formed are eventually converted into the lysosomes and ultimately result in the drug release [102]. Liu et al. developed SWCNT conjugated with paclitaxel (PTX) and reported the nonreceptor mediated endocytosis mechanism for the cellular uptake in murine 4T1 breast carcinoma cells [110].

Islam et al. investigated the cellular uptake of pluronic copolymer-stabilized, purified $\sim 145 \mathrm{~nm}$ long single walled carbon nanotubes (SWCNTs) through a series of complementary cellular, cell-mimetic, and in vitro model membrane experiments. The Raman intensity distribution, obtained from the G-band $\left(1590 \mathrm{~cm}^{-1}\right)$, shows SWCNT concentration localized to the midplane of a fixed, hematoxylin-labelled cell. SWCNTs were preferentially located within cells versus the extracellular regions, and most SWCNTs were localized in the perinuclear region. SWCNTs localized within fluorescently labelled endosomes and confocal Raman spectroscopy showed a dramatic reduction in SWCNT uptake into the hematoxylin-labeled $\mathrm{HeLa}$ cell at $4^{\circ} \mathrm{C}$ compared with $37^{\circ} \mathrm{C}$, after being incubated for 2 days. These data suggested energy-dependent endocytosis. To confirm this, a direct measurement to check the endocytosis was conducted in which endocytosis in HeLa cells was visualized using a Green Fluorescent Protein, GFP-tagged RhoB-GTPase, which labels endosomes in mammalian cells. On confocal imaging it was confirmed that the internalization of SWCNTs was occurring through the endocyte formation as there was a slight increase in endosome numbers per cell with increased time of exposure to SWCNTs, with a statistically significant increase in endosome number at 20 and 25 minutes [111].

In endocytosis independent pathway there is a direct translocation of CNT through the plasma membrane into the cytoplasm which has been termed by some researchers as the "nanoneedle" mechanism [100]. This pathway includes processes such as diffusion, membrane fusion, and direct pore transport (Figure 5(c)). Individually dispersed CNTs in aqueous solutions have been experimentally demonstrated to be able to enter the cytoplasm of cells by directly crossing the cell membrane. Such cellular uptake of CNT, which is not influenced by the presence of endocytosis inhibitor (such as sodium azide), suggests the endocytosis independent pathway of internalization [112]. The mechanism of how CNT enters cells via the insertion and diffusion is poorly understood. Some theoretical studies suggest a two-step process in which, first, the tubes accommodate onto the lipid cell membrane and then orient to adopt the transmembrane configuration. In this model, the internalization of nanotubes into the cells was spontaneous and was mediated by the lipid membrane and that the hydrophilic interactions and/or static charge interactions between the tubes and the lipid membrane which drove the translocation of the nanotubes [113]. The conformation of CNT perpendicular to the plasma membrane during uptake suggested a mechanism similar to nanoneedles, which perforate and diffuse through the lipid bilayer of the plasma membrane without inducing cell death [79]. Rawson et al. reported the first demonstration of a direct interface of vertically aligned SWCNTs (VASWCNTs) with eukaryotic RAW 264.7 mouse macrophage cell line. VASWCNTs entered the cells naturally due to its needle-like structure without application of any external force owing to endocytosis independent pathway for internalization [114].

\section{Application of CNTs in Cancer Treatment}

For decades, human immortal cancer cell lines have constituted an accessible, easily usable set of biological models with which to investigate cancer biology and to explore the potential efficacy of anticancer drugs is of less tedious work. Currently, various ex vivo studies, such as cell line studies, cellular uptake studies, fluorescent microscopy, and flow cytometry, are carried out for this purpose.

Various cancer cell lines were cultured with modified CNTs (functionalization on the surface and ends of the CNTs, and by conjugating CNTs with ligands) and evaluated for therapeutic efficacy, cell viability, cell survival assays, and cell apoptosis. Ex vivo studies specifically used in the evaluation of CNTs for cancer chemotherapy are shown in Table 1.

5.1. Brain Cancer. Brain cancer is the leading cause of cancer-related death in the US in patients under the age of 35. Anaplastic astrocytomas (Grade III) and glioblastomas (Grade IV) are most aggressive brain cancers with survival period of 24 and 9 months, respectively [138]. Children who survive their brain cancers (mainly medulloblastomas) often 


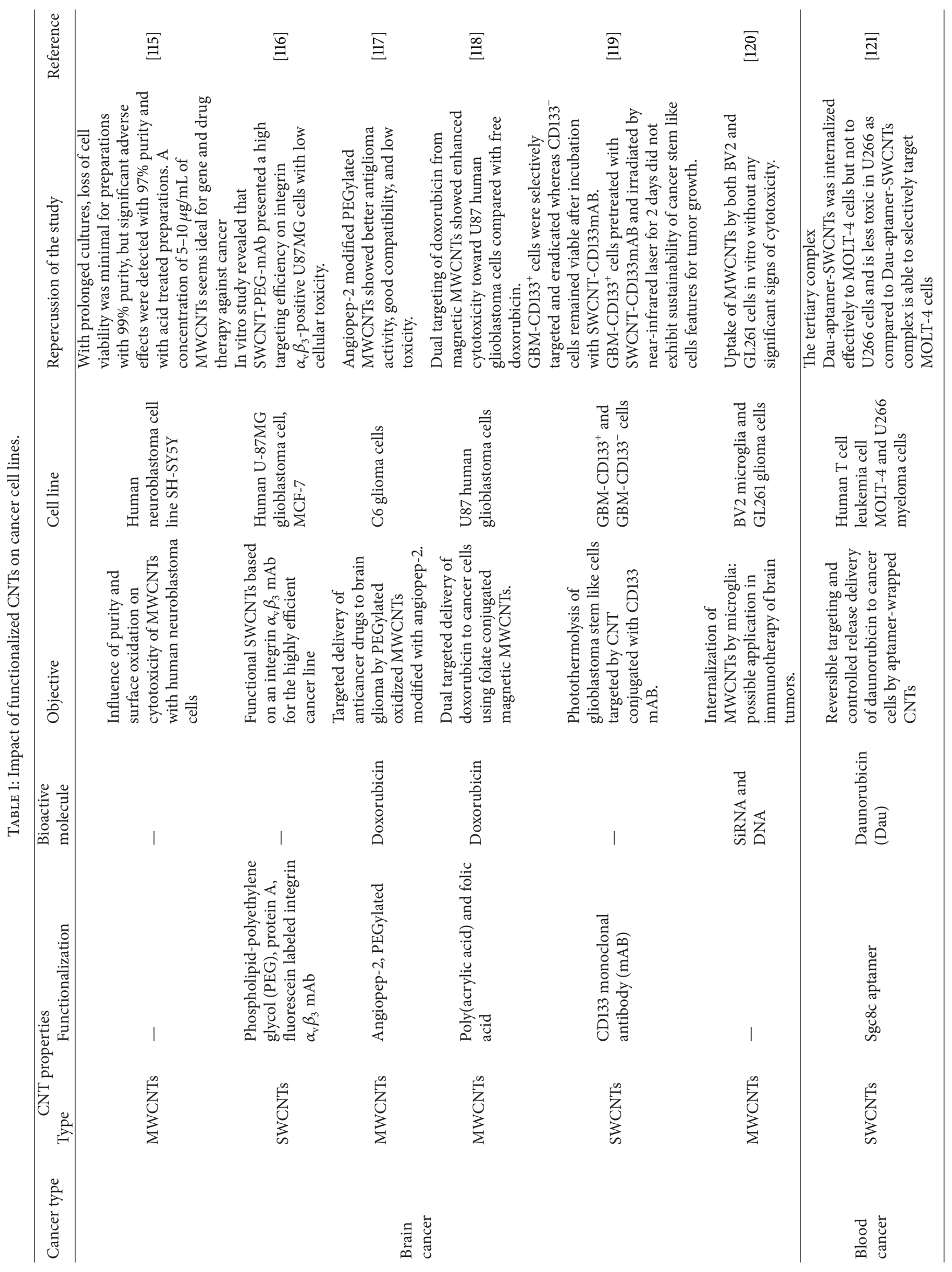




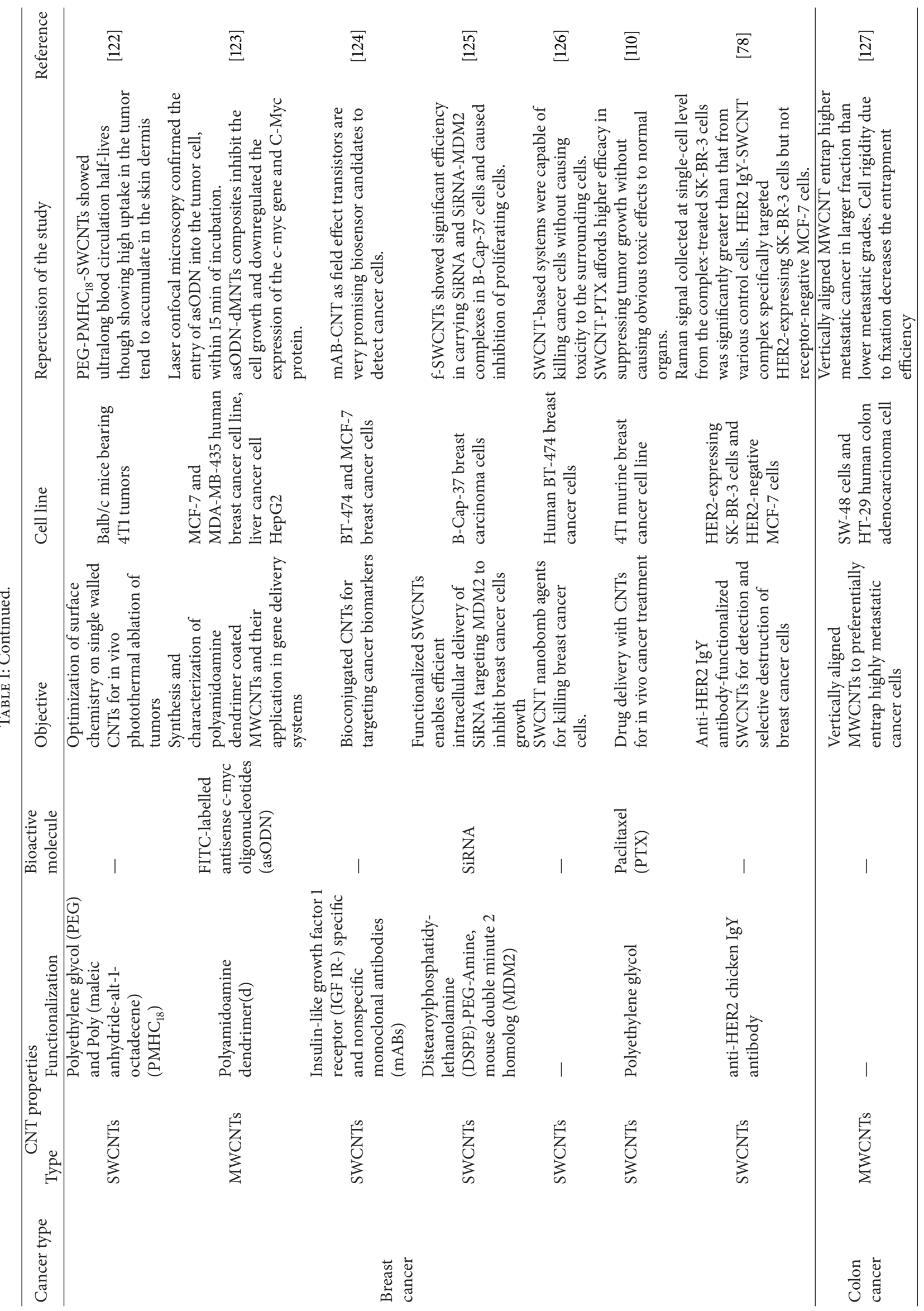




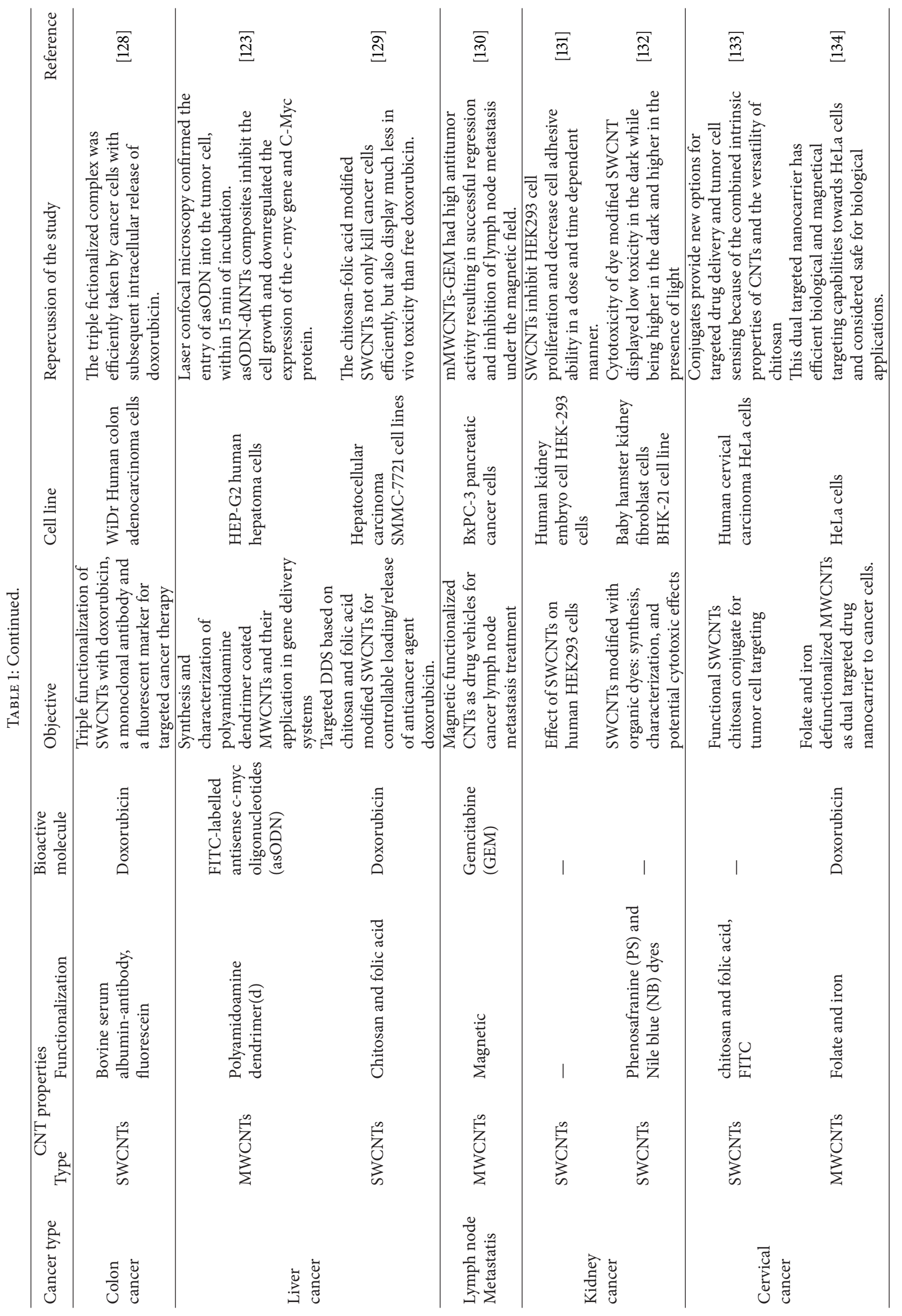




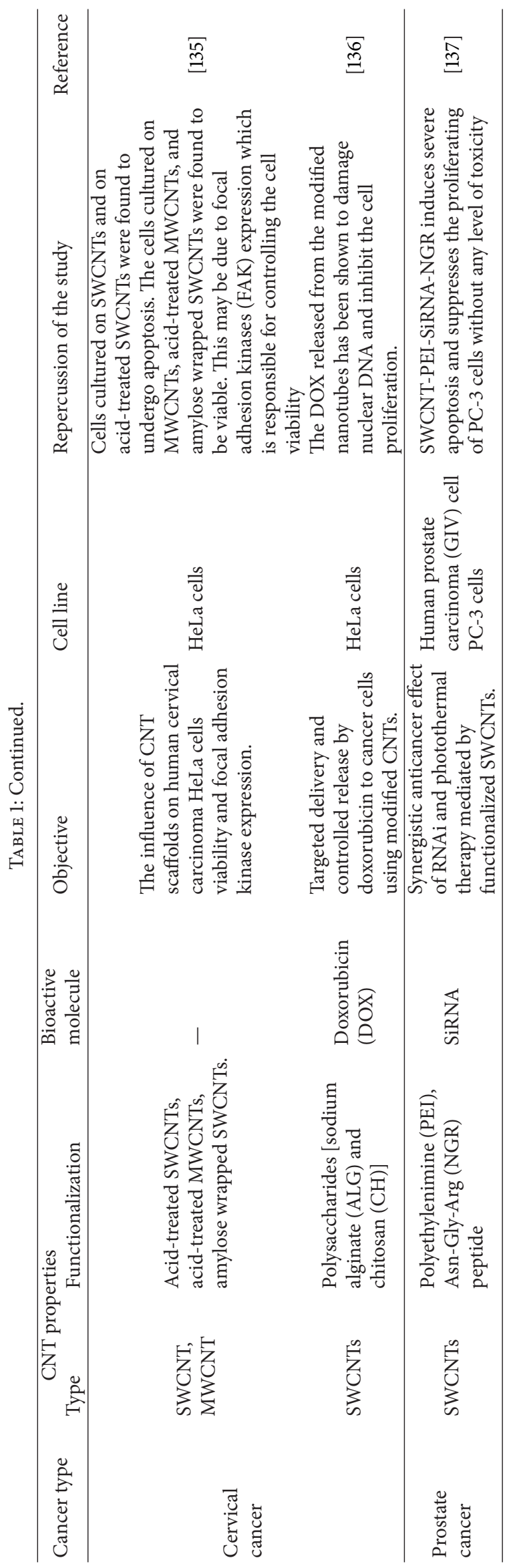


suffer substantial adverse effects related to the toxicities of therapy on the developing nervous system [139]. Currently available systemic chemotherapy is less effective due to presence of the blood-brain barrier (BBB) which restricts the penetration of most drugs into the brain. Recently, a number of CNT-based targeting approaches have been developed for the treatment of brain cancer and a brief account is presented below.

Vittorio et al. investigated the biocompatibility of MWCNTs with cultured Human neuroblastoma cells SH-SY5Y. Reactive oxygen species (ROS) are chemically reactive molecules containing oxygen. ROS can damage cellular proteins, lipids, and DNA leading to fatal lesions in cells that contribute to carcinogenesis. In vitro experiments showed loss of cell viability was minimal with no intracellular ROS detected with prolonged cultures and continued propagation in the presence of $99 \%, 97 \%$ pure MWCNTs and acidtreated $97 \%$ pure MWCNTs but no significant decrease in the proliferation of cells incubated for 3 days was observed with the cells cultured with $99 \%$ pure MWCNTs. After conducting WST-1 assay it was assessed that, on increasing the concentration of MWCNTs from $5 \mu \mathrm{g} / \mathrm{mL}$ to $500 \mu \mathrm{g} / \mathrm{mL}$, purity and surface oxidation of MWCNTs seem to downregulate the \% cell viability and at $5 \mu \mathrm{g} / \mathrm{mL} 100 \%$ cells are viable. Hence it was concluded that the concentration of $5-10 \mu \mathrm{g} / \mathrm{mL}$ seems ideal for gene and drug therapy against cancer [115].

Xing et al. synthesized phospholipid-bearing polyethylene glycol (PL-PEG) functionalized SWCNTs conjugated with protein $A$ which was further coupled with the fluorescein-labeled integrin $\alpha_{\mathrm{v}} \beta_{3}$ monoclonal antibody to form SWCNT-integrin $\alpha_{\mathrm{v}} \beta_{3}$ monoclonal antibody (SWCNTPEG-mAb). Confocal microscopy revealed that SWNT-PEG$\mathrm{mAb}$ showed a much higher fluorescence signal on integrin $\alpha_{\mathrm{v}} \beta_{3}$-positive U87MG cells and presented a high targeting efficiency with low cellular toxicity, while, for integrin $\alpha_{v} \beta_{3}$-negative MCF-7 cells, no obvious fluorescence was observed which clearly reveals low targeting efficiency of the functionalized SWCNTs, demonstrating that the specific targeting of integrin $\alpha_{\mathrm{v}} \beta_{3}$-positive U87MG cells was caused by the specific recognition of integrin $\alpha_{\mathrm{v}} \beta_{3}$ on the cellular membrane by the $\alpha_{\mathrm{v}} \beta_{3}$ monoclonal antibody [116].

Oxidized MWCNTs cannot only be distributed in the brain but may accumulate in tumors after conjugating with specific ligands and also possess an ultrahigh surface area for efficient loading of anticancer drug. Ren et al. developed a dual targeting PEGylated MWCNTs and loaded with a targeting ligand angiopep 2 (ANG) and doxorubicin, respectively, to target low density lipoprotein receptor-related protein receptor which is overexpressed on the blood brain barrier (BBB) and C6 glioma cells. In vitro intracellular tracking and in vivo fluorescence imaging demonstrated the ideal dual targeting of the developed system which was attained by the higher transcytosis capacity and parenchymal accumulation by the angiopep- 2 and can be considered a material of choice to cross blood brain barrier as well as to specifically recognise their lipoprotein receptors present on the glioma cells for directing the site specific release of anticancer drug. C6 cytotoxicity, hematology analysis, and CD68 immunohistochemical analysis reveals better antiglioma effect with good biocompatibility and low toxicity of O-MWCNTs-PEGANG, compared with that of free doxorubicin [117].

The existence of cancer stem cells (CSCs) or stem-like cancer cells (SLCCs) is regarded as the cause of tumor formation and their recurrence. However, the origin of such cells remains controversial with two competing hypotheses: CSCs are either transformed tissue adult stem cells or dedifferentiated from transformed progenitor cells [140]. Wang et al. explored the potential of CD133 monoclonal antibody (anti-CD133) conjugated SWCNTs for therapeutic targeting of CD133 CSCs. Glioblastoma (GBM)-CD133 ${ }^{+}$cells were selectively targeted and eradicated whereas GBM-CD133cells remained viable. Furthermore, anti-CD133-SWCNTs pretreated GBM-CD133 ${ }^{+}$cells were irradiated with nearinfrared laser for 2 days and showed no sign of sustainability of CSCs for tumor growth after xenotransplantation in nude mice. From this report it is stated that monoclonal antibody conjugated SWCNTs are capable of selectively targeting the CSCs as well as blocking their recurrence [119].

5.2. Blood Cancer. Leukemia is a cancer that begins in the bone marrow (the soft inner part of some bones), but in most cases, moves into the blood. It can then spread to other parts of the body, such as organs and tissues. Acute lymphoblastic leukemia (ALL), one of the four main types of leukemia, is a slow-growing blood cancer that starts in bone marrow cells called lymphocytes or white blood cells. Once these white blood cells are affected by leukemia, they do not go through their normal process of maturing. The lymphocytes continue to reproduce and build up and invade the blood fairly quickly. ALL is an aggressive type of leukemia; without treatment, most patients with acute leukemia would live only a few months [141].

An enhanced targeted delivery of daunorubicin (Dau) to acute lymphoblastic leukemia was achieved by Taghdisi et al., they developed a tertiary complex of Sgc8c aptamer, daunorubicin, and SWCNT named as Dau-aptamer SWCNTs. Flow cytometric analysis showed that the tertiary complex was internalized effectively into human $\mathrm{T}$ cell leukemia cell (MOLT-4 cells) but not to U266 myeloma cells [121].

5.3. Breast Cancer. Breast cancer (BC) has become the most common malignancy and the leading cause of cancer-specific death in women, according to GLOBOCAN 2008 estimates [142]. Overexpression of human epidermal growth factor receptor 2 (HER2), also known as c-erbB-2 or HER2/neu, is approximately $20 \%-25 \%$ responsible for invasive BC. With an increasing understanding of the role of HER2 in tumor proliferation, angiogenesis, and metastasis, novel special treatment strategies for this HER2-positive subtype of BC have been validated and are increasingly used in clinical practice. One of the most important treatment strategies is to block the signal pathway of HER2/neu; this is defined as targeted therapy [143].

In a study, Pan et al., investigated the efficiency of MWCNTs to deliver gene to the tumor cell for cancer therapy. In this work, they fabricated MWCNTs modified 
with polyamidoamine dendrimer which were further conjugated with FITC-labelled antisense c-myc oligonucleotides (asODN). Human breast cancer cell line MCF-7 cells and MDA-MB-435 cells were incubated with modified MWCNTs (asODN-dMNTs). Fluorescence developed by the FITC revealed the cellular uptake of asODN-dMNTs within 15 min. These composites inhibit the cell growth in time and dose dependent means and downregulated the expression of cmyc gene (overexpression of this gene amplify the expression of HER2) and C-Myc protein [123].

A chemically functionalized SWCNT carrier has been developed for the effective delivery of SiRNA and SiRNAMDM2 complexes to the breast carcinoma B-Cap-37 cells. Results proved the high efficiency of F-SWCNT in carrying SiRNA to the carcinoma cells and the new F-SWCNT-SiRNAMDM2 complexes caused $44.53 \%$ inhibition of proliferating B-Cap-37 carcinoma cells for 72 hours by downregulating the expression of c-myc gene [125].

Panchapakesan et al. discovered the explosive nature of SWCNT which can act as a potent therapeutic nanobomb agents for killing breast cancer cells. In his work, he adsorbed water molecule on the SWCNT, which upon exposure to laser light of $800 \mathrm{~nm}$ at light intensities of approximately $50-200 \mathrm{MW} / \mathrm{cm}^{2}$ which is sufficient to transform optical energy to thermal energy and cause the evaporation of water molecules which built extreme pressure in SWCNT causing them to explode in the suspension of human BT-474 breast cancer cells in phosphate buffered saline solution and render the cells to death. The presence of bubbles around the dead cells revealed the boiling effect caused by SWCNT explosions [126].

A water soluble SWCNT-Paclitaxel (PTX) conjugate has been developed by conjugating PTX to functionalized polyethylene glycol SWCNTs via a cleavable ester bond. SWCNT-PTX has been found to be highly efficient in suppressing tumor growth when compared with clinical taxol in a murine $4 \mathrm{Tl}$ breast cancer cells, which has been attributed to the extended blood circulation (due to PEGylation) and tenfold higher tumor PTX uptake by SWCNT delivery, probably through enhanced permeability and retention (EPR) effect [110].

5.4. Colon Cancer. Colorectal cancer is the leading cause of death amongst the men and women worldwide and afflicts more than 135,000 patients per year in America. This cancer has usually been viewed as a homogeneous entity rather than a complex heterogeneous disease developing through multiple genetic and epigenetic abnormalities, such as defective DNA mismatch repair (dMMR) and the $\mathrm{CpG}$ island methylator phenotype (CIMP) [144].

Abdolahad et al. utilize the vertical arrays of MWCNTs for entrapping the metastatic human colon adenocarcinoma SW-48 cells and HT-29 cancerous cells. Due to the extreme deformability and softness of higher metastatic malignant cells, they exhibit higher fraction of entrapment by the vertically aligned MWCNTs as compared to the less deformable and rigid lower grades of metastatic cancerous cells. This new application of MWCNTs distinguishes the healthy and highly deformable cancerous cells more precisely than SWCNTs and also showed better delivery of anticancer drugs to these cancer cells [127].

Triple functionalized SWCNTs were fabricated with an anticancer drug (Doxorubicin), a monoclonal antibody and a fluorescent marker (fluorescein) at the noncompetitive binding sites on the SWCNTs for targeting the cancer cells. Confocal laser microscopy reveals the bovine serum albuminantibody specific receptor mediated uptake of SWCNTs by the human colon adenocarcinoma cell WiDr cells with subsequent targeting of doxorubicin intracellularly to the nucleus [128].

5.5. Liver Cancer. Hepatocellular carcinoma (HCC) is a highly prevalent malignancy, especially in Asia. Liver cirrhosis is the strongest predisposing factor for HCC, accounting for approximately $80 \%$ of patients with this disease. In the United States, Europe, and Japan, hepatitis C virus (HCV) infection is the major etiology of liver cirrhosis and HCC. Hepatitis virus B (HBV) infection, however, is the leading cause of HCC development in most Asian countries other than Japan. In addition to HBV and HCV infection, alcoholic cirrhosis and metabolic disorders can also act as risk factors for HCC [145]. c-Myc is among the most frequently overexpressed genes in human cancers. Overexpression of c-Myc in hepatic cells leads to the development of hepatocellular carcinoma [146]. However, an attempt has been made by Pan et al. to suppress the expression of c-myc gene and C-Myc protein in the tumor bearing cell.

Polyamidoamine dendrimer modified CNTs (dMWCNTs) were fabricated for the efficient delivery of antisense c-myc oligonucleotide (asODN) into liver cancer cell line HepG2 cells. asODN-dMWCNTs composites were incubated with HepG2 cells and confirmed to enter into tumor cells within $15 \mathrm{~min}$ by laser confocal microscopy. These composites inhibited the cell growth in time and dose dependent means and downregulated the expression of the c-myc gene and CMyc protein. These composites exhibit maximal transfection efficiencies and inhibition effects on tumor cells when compared to $\mathrm{CNT}-\mathrm{NH}_{2}$-asODN and dendrimer (asODN) alone [123].

Meng et al. constructed a highly effective targeted DDS based on chitosan and folic acid modified SWCNTs for controllable loading/release of anticancer agent doxorubicin (DOX). The obtained DDS not only effectively killed the hepatocellular carcinoma SMMC-7721 cell lines and depressed the growth of liver cancer but also displayed much less in vivo toxicity than free doxorubicin [129].

5.6. Lymph Node Metastasis. The presence of lymph node invasion is one of the strongest indicators for prognoses of distant metastasis and survival in most cancers. In the multistep process of cancer metastasis development, invasion into a vascular or a lymphatic system has generally been believed to be a key step of tumor cell dissemination. Once tumor cells acquire abilities of intravasation and survival in an unfavorable vascular environment, they circulate around 
the whole body parts to form new tumors at the secondary site [147]. Lymph node metastasis is a powerful predictor of recurrence and death in patients with cutaneous melanoma. Metastasis to regional lymph nodes develops during the course of the disease in approximately $30 \%$ of patients with cutaneous melanoma [148].

Yang et al. compared the in vitro and in vivo potential therapeutic effect of gemcitabine (GEM) loaded magnetic MWCNTs (mMWCNTs) with that of gemcitabine loaded magnetic-carbon particles (mACs). His finding reflects the high antitumor activity in human pancreatic cancer BxPC3 cells of both the systems when compared along with free drug. Due to superparamagnetic behaviour of mMWCNTsGEM, their magnetic moments tend to align along the applied field leading to net magnetization which greatly affects the interaction of mMWCNTs-GEM with the cellular membrane and thus they were found to be superior than mACs-GEM in successful inhibition of lymph node metastasis after following subcutaneous administration under the impact of magnetic field [130].

5.7. Kidney Cancer. Renal cell carcinoma (RCC) is responsible for approximately $80 \%$ of primary renal cancers, and urothelial cell carcinoma (UCC) accounts for the majority of the remainder $(20 \%)$. The most common histological subtype of RCC is the conventional or clear cell (ccRCC). The occurrence of ccRCC is due to the defunctioning of the Von Hippel-Lindau (VHL) tumor suppressor gene (TSG), located on chromosome $3 \mathrm{p}$. Loss of functioning of the VHL protein leads to stabilization of hypoxia-inducible factors and nuclear transcription factors that in turn can activate the transcription of many genes including those encoding vascular endothelial growth factor (VEGF) and platelet derived growth factor [149]. RCC is a highly aggressive tumor and also the most lethal of urologic malignancies with an estimated 88,400 new cases and 39,300 kidney cancer-related deaths from RCC in Europe [150].

Cui et al. investigated the interaction between SWCNTs and human embryo kidney HEK-293 cells intended to explore SWCNT biocompatibility and safety. It was found that SWCNTs can inhibit the proliferation of HEK-293 cells, induce the cell apoptosis, and decrease cell adhesive ability in a time and dose dependent manner. SWCNTs induce changes in the cell cycle which could be attributed to the decrease in the number of cells in the S-phase due to upregulated expression of P16 which inhibits the cyclin dependent kinase activity of $\mathrm{CdK} 2, \mathrm{CdK} 4$, and $\mathrm{CdKr}$ and therefore prevents the cells from entering an S-phase and subsequently arresting the cell cycle in the G1 phase [131].

5.8. Cervical Cancer. Oncogenic human papillomavirus (HPV) has a causal role in nearly all cervical cancers and in many vulvar, vaginal, penile, and oropharyngeal cancers. HPV types 16 and 18 are majorly responsible for $70 \%$ of cervical cancers [151]. In HPV-associated cancers, oncogenic antigens E6 and E7 were overexpressed on the tumor cells and thus, they represent an ideal target for developing antigen-specific immunotherapy for the control of cervical cancer [152].

$\mathrm{Wu}$ et al. developed a novel approach of utilizing natural biocompatible polymer chitosan for imaging the tumor cells. In this assay, SWCNTs were modified by chitosan (CHIT) fluorescein isothyocyanate (FITC). This was further conjugated with folic acid (FA), as mostly cancers cells overexpress folic acid receptors, to construct the functional FITC-CHITSWCNT-FA conjugate. These novel functionalized SWCNTs were found to be soluble and stable in phosphate buffer saline and can be readily transported inside the human cervical carcinoma HeLa cells. Combining the intrinsic properties of CNTs, versatility of chitosan, and folic acid, FITC-CHITSWCNT-FA can be used as potential devices for targeting the drug into the tumor cells and also for imaging them [134].

Five types of CNTs suspensions were prepared by Zhang et al., by dispersing SWCNTs, acid-treated SWCNTs, MWCNTs, acid treated MWCNTs, and amylose wrapped SWCNTs, individually in water, and the influence of these scaffolds on human cervical carcinoma HeLa cells was investigated by WST-1 assay, acridine orange/ethidium bromide double staining, and $1,1^{\prime}$-dioctadecyl-3,3,3',3' tetramethylindocarbocyanine perchlorate staining. The results indicated that both "dot like" and "dash like" focal adhesion kinases (FAKs) were mainly distributed at the periphery of the cells cultured on SWCNTs and on acid-treated SWCNTs and due to this they were found undergoing apoptosis with damaged cell membrane and condensed chromatin; however, cells cultured on MWCNTs, acid-treated MWCNTs, and amylose wrapped SWCNTs were found to be viable which is due to the distribution of "dot like" focal adhesion kinases (FAKs) in the whole cell body of the cells [135].

5.9. Prostate Cancer. Prostate cancer is a slow growing cancer and early propagation of cancer cells occurs before the disease become clinical. Cases of prostate cancer in USA estimates 238,590 in the year 2013 out of which 29,720 cases of death due to prostate cancer have been reported in SEER stat facts sheet published by National Cancer Institute, USA [153]. Prostate cancer antigen 3 (PCA3) has been validated as the principal molecule associated with prostate cancer (PCa). The PCA3 gene is located on the chromosome 9q21-22 and was molecularly characterized as the prostate cancerspecific gene, highly overexpressed in almost all prostate tumor specimens and PCa metastasis. Here we discuss a study using human prostate cancer cell line with respect to CNTs [154].

Li et al. developed a novel targeting SiRNA delivery system by using SWCNTs which was chemically functionalized with polyethylenimine and bound by DSPE-PEG 2000 maleimide for further conjugation with tumor targeting Asn-Gly-Arg (NGR) peptide. This novel system efficiently crosses human prostate cancer cell PC-3 cell membrane in vitro and induces more severe apoptosis and suppression in the proliferating cells. The combination of near-infrared photothermal therapy and RNAi significantly enhanced the 
antitumor activity without causing toxicity to other organs [137].

\section{Toxicological Assessment of CNTs}

Despite of the exciting prospects of CNTs in drug delivery, there are some factors which limit the applications of CNTs. Presence of impurities, nonuniformity in morphology and structure, large surface area (leads to protein opsonization), hydrophobicity, insolubility, and tendency of CNTs to bundle together are some obstacles for their nanomedical applications $[23,155]$.

Another key obstacle is the toxicity of CNTs. Entrance into the body is physical, and usually few nanoparticles enter the body; however, once there, they are persistent due to their limited metabolisms, so their removal is slow, and chronic cumulative health effects are studied. The underlying mechanisms of CNT toxicity include oxidative stress, production of cytokines, chemokines and inflammatory responses, malignant transformation, DNA damage and mutation (errors in chromosome number as well as disruption of the mitotic spindle), the formation of granulomas, and interstitial fibrosis $[156,157]$.

In view of carcinogenicity of CNTs, SWCNTs were directly instilled into the lungs of the animals, it was found that exposure to SWCNTs at a high concentration leads to the development of granulomas in rodents and a concentration of $0.5 \mathrm{mg} / \mathrm{m}^{3}$ and $2.5 \mathrm{mg} / \mathrm{m}^{3}$ for MWCNTs induces microgranulomas with the inflammation in the alveoli [158160]. Similarly, in a study by Kanno et al., demonstrated the carcinogenic potential of MWCNT to induce multiple mesothelioma with severe peritoneal adhesion when administered intraperitoneally to $\mathrm{p} 53$ heterozygous mice. This may be due to its structural similarities (size/shape) to asbestos as well as persistency in the organism, while in an another study reported by Takanashi et al., and it was stated that subcutaneously implanting the MWCNTs in to the rasH2 mice did not develop neoplasm [161-163].

In view to the inflammatory responses with CNTs, Monteiro-Riviere et al. exposed human epidermal keratinocytes (HEK) to MWCNTs and found that MWCNT induces the release of proinflammatory cytokine interleukin 8 from HEK which indicates the irritation response on target epithelial cells [164]. Similarly, upon subcutaneously administering MWCNT at $0.1 \mathrm{mg} / \mathrm{kg}$ and $1 \mathrm{mg} / \mathrm{kg}$ showed acute inflammation characterized by vasodilatation, edema formation, neutrophil infiltrate, tissue damage and also elicited hyperalgesic response (as seen by the increase paw withdrawal of animal) [165]. In a study, Pons et al. investigated the immunomodulatory activity of MWCNTs in peripheral blood mononuclear cells (PBMCs) from healthy donors and mite-allergic subjects. It was observed that MWCNTs may either promote or suppress immune responses with the type of Toll-like receptor agonist the cells are stimulated with. Basal secretion of all TNF- $\alpha$, IL-2, IL-5, IL-6, IL-12/23p 40 , or IFN- $\gamma$ was not altered by MWCNTs in PBMCs derived from both healthy donors and allergic subjects but significantly increased in the release of TNF- $\alpha$, IL- 6 , and IL-12/23p40 was observed in PBMCs stimulating the Toll-like receptor (TLR2, TLR3, and TLR4) agonist [166].

Among the many toxicity pathways, interference with cytoskeleton and fibrous mechanisms, cell signalling, and membrane perturbations are some of the effects resulting from exposure to CNTs [157]. In a study, exposure of MWCNT to the coculture of SAEC (small airway epithelial cells), a Type II epithelial cell, and HMVEC (human microvascular endothelial cells), increases the VEGFA (vascular endothelial growth factor), soluble adhesion molecules (sICAM-1 and sVCAM-1) protein levels, as well as increases the intracellular phospho-NF- $\kappa$ B, phosphoStat3, and phospho-p38 MAPK (mitogen-activated protein kinases) which tends to induce multiple changes in the endothelial cell barrier, including an increase in reactive oxygen species, actin rearrangement, loss of VE-cadherin (vascular endothelial) at the cell surface, and an increase in endothelial angiogenic ability [167].

It was reported that length of MWCNTs was found to exert effects on the biomembranes; when the distribution of MWCNTs (3-14 $\mu \mathrm{m}$ length) in RAW264 cells was observed under a light microscope, MWCNTs were located on the surface of the plasma membrane and a portion of them seemed to be stucked on it which tends to increase the permeability defects of the plasma membrane lipid bilayer while shorter $(1.5 \mu \mathrm{m})$ MWCNTs were significantly less toxic $[168,169]$. In a study, interference of CNTs with cytoskeleton was investigated by Shvedova et al., and exposure of cultured human epidermal keratinocytes (HaCaT) to SWCNTs induces oxidative stress and results into loss of cell viability, indicating that dermal exposure to CNTs may lead to these altered skin conditions [170].

Not only bare CNTs showed toxicity, but also functionalized CNTs were also reported to cause toxicities; as in a study by Tian et al., covalently functionalized MWCNTs with carboxylate $(\mathrm{COOH})$, polyethylene glycol (PEG), amine (NH2), side-wall amine (sw- $\mathrm{NH}_{2}$ ), and polyetherimide (PEI), respectively, were screened for toxicity in bronchial epithelial cells and BEAS-2B and TPH-1 cells. It was observed that anionic functionalization ( $\mathrm{COOH}$ and $\mathrm{PEG})$ decreased the production of profibrogenic cytokines and growth factors (including IL-1B, Transforming growth factor beta 1 (TGF-B1) and platelet derived growth factor-AA (PDGF-AA)), while neutral and weak cationic functionalization $\left(\mathrm{NH}_{2}\right.$ and sw$\mathrm{NH}_{2}$ ) showed intermediary effects. In contrast, the strongly cationic PEI functionalized MWCNTs induced biological effects. Compared to pristine MWCNTs, strong cationic PEIMWCTs induced significant lung fibrosis, while carboxylation significantly decreased the extent of pulmonary fibrosis [171]. But the toxicity of f-MWCNTs at varying degrees of carboxylation was assessed by Jain et al., in a murine macrophage RAW 264.7 cell line, a model for liver Kupffer cells. Increased in vitro cytotoxicity was found to be directly proportional to carboxylation density which was associated with a concurrent increase in the number of apoptotic cells and production of reactive nitrogen species (RNS) and reactive oxygen species (ROS) [172].

Acid-functionalized SWCNTs induce adverse effects in murine peritoneal macrophages which were related to the 
conversion of microtubule-associated protein light chain 3, LC3-I to LC3-II, and the accumulation of SWCNT in macrophage lysosomes, leading to lysosome membrane destabilization, which indicates reduced autophagic degradation [173]. Campagnio et al. studied the toxicity of PEGylated SWCNTs in pregnant mice. A dose of $10 \mu \mathrm{g} /$ mouse has no adverse effects both on embryos and dams but at a dose of $30 \mu \mathrm{g} / \mathrm{mouse}$, and teratogenic effects associated with placental damage were detected both in embryos and dams (dose given as a single bolus or as multiple doses). Hepatic damage in dams was seen only in the multiple exposure groups. PEGylated SWCNTs reached the conceptus when administered early in pregnancy and at later stages it was detected in the placenta and the yolk sac but not in embryo [174].

Before the widespread utilization of CNTs in the medical science, it is important to note that the chronic toxicity of CNT must be experimentally studied and the appropriate safeguards must be taken against the possible interactions among the CNTs and biological systems.

\section{Conclusion}

CNT represents a novel class of carriers for the delivery of drugs in a site specific and target oriented manner. CNTs possess extraordinary physical, chemical, and mechanical properties, which make them as a potent biological carrier to deliver anticancer drugs. Studies have clearly shown that functionalization of CNT and further derivatization with biodegradable polymers render them compatible with biological systems. Due to their unique chemistry, hexagonal arrangement of carbon atoms, various sites are available for both covalent and noncovalent functionalization with the therapeutically active molecule or protein macromolecules which envisaged the potential of CNT as nanocarrier for the site specific delivery of therapeutic agent including peptides, proteins, nucleic acid, and other small drug molecules for targeting various cancer cells. These functionalized CNTs possess high propensity to traverse cell membrane either via endocytosis dependent or independent pathways.

Thorough investigations have been performed in this review on various synthesis and modification routes for the production of purified CNTs and their role in combating cancer. Various ex vivo models based on different cancer cell lines were studied to determine the pharmacokinetic and pharmacodynamic parameters of anticancer compounds, that is, being carried by the biocompatible nanosized carbon tubes at the targeted site on cancer cells. All the observations and results cited in this review evidently endorse the usefulness of functionalized CNTs as a potential carrier for the anticancer molecule to target the cancer cell without causing toxicity to other viable cells. Also, the usefulness of cell lines has greatly validated the results for the assessment of in vivo therapeutic and diagnostic efficacy for cancer treatment and reduces the dependency on animal and human models for the treatment of cancer at the preclinical and clinical study trial level. This compilation of the literature provides useful information to researchers for exploring the further scope of CNTs in the medical science.

\section{Conflict of Interests}

The authors declare that there is no conflict of interests regarding the publication of this paper.

\section{References}

[1] S. Iijima, "Helical microtubules of graphitic carbon," Nature, vol. 354, no. 6348, pp. 56-58, 1991.

[2] A. M. A. Elhissi, W. Ahmed, I. Ul Hassan, V. R. Dhanak, and A. D'Emanuele, "Carbon nanotubes in cancer therapy and drug delivery," Journal of Drug Delivery, vol. 2012, Article ID 837327, 10 pages, 2012.

[3] K. Kostarelos, L. Lacerda, C. D. Partidos, M. Prato, and A. Bianco, "Carbon nanotube-mediated delivery of peptides and genes to cells: translating nanobiotechnology to therapeutics," Journal of Drug Delivery Science and Technology, vol. 15, no. 1, pp. 41-47, 2005.

[4] C. Journet, W. K. Maser, P. Bernier et al., "Large-scale production of single-walled carbon nanotubes by the electric-arc technique," Nature, vol. 388, no. 6644, pp. 756-758, 1997.

[5] A. G. Rinzler, J. Liu, H. Dai et al., "Large-scale purification of single-wall carbon nanotubes: process, product, and characterization," Applied Physics A: Materials Science \& Processing, vol. 67, no. 1, pp. 29-37, 1998.

[6] A. M. Cassell, J. A. Raymakers, J. Kong, and H. Dai, "Large scale CVD synthesis of single-walled carbon nanotubes," The Journal of Physical Chemistry B, vol. 103, no. 31, pp. 6484-6492, 1999.

[7] P. Nikolaev, M. J. Bronikowski, R. K. Bradley et al., "Gasphase catalytic growth of single-walled carbon nanotubes from carbon monoxide," Chemical Physics Letters, vol. 313, no. 1-2, pp. 91-97, 1999.

[8] M. S. Dresselhaus, G. Dresselhaus, and P. C. Eklund, Science of Fullerenes and Carbon Nanotubes, Academic Press, San Diego, Calif, USA, 1996.

[9] T. W. Ebbesen and P. M. Ajayan, "Large-scale synthesis of carbon nanotubes," Nature, vol. 358, no. 6383, pp. 220-222, 1992.

[10] C. N. Rao and A. Govindaraj, "Carbon nanotubes from organometallic precursors," Accounts of Chemical Research, vol. 35, no. 12, pp. 998-1007, 2002.

[11] Z. F. Ren, Z. P. Huang, J. W. Xu et al., "Synthesis of large arrays of well-aligned carbon nanotubes on glass," Science, vol. 282, no. 5391, pp. 1105-1107, 1998.

[12] Z. H. Xia, P. R. Guduru, and W. A. Curtin, "Enhancing mechanical properties of multiwall carbon nanotubes via $s p^{3}$ interwall bridging," Physical Review Letters, vol. 98, no. 24, Article ID 245501, 2007.

[13] F. S. Garmaroudi and R. A. R. Vahdati, "Functionalized CNTs for delivery of therapeutics," International Journal of Nano Dimension, vol. 1, no. 2, pp. 89-102, 2010.

[14] L. Serpe, Conventional Chemotherapeutic Drug Nanoparticles for Cancer Treatment, Nanotechnologies for the Life Sciences, Wiley-VCH, Weinheim, Germany, 2006.

[15] K. T. Nguyen, "Targeted nanoparticles for cancer therapy: promises and challenges," Journal of Nanomedicine \& Nanotechnology, vol. 2, no. 5, Article ID 1000103e, 2011.

[16] M. Mahmood, A. Karmakar, A. Fejleh et al., "Synergistic enhancement of cancer therapy using a combination of carbon nanotubes and anti-tumor drug," Nanomedicine, vol. 4, no. 8, pp. 883-893, 2009. 
[17] M. Ferrari, "Cancer nanotechnology: opportunities and challenges," Nature Reviews Cancer, vol. 5, no. 3, pp. 161-171, 2005.

[18] S. Prakash, M. Malhotra, W. Shao, C. Tomaro-Duchesneau, and S. Abbasi, "Polymeric nanohybrids and functionalized carbon nanotubes as drug delivery carriers for cancer therapy," Advanced Drug Delivery Reviews, vol. 63, no. 14-15, pp. 13401351, 2011.

[19] G. Chashoo, S. K. Singh, N. A. Qazi, and A. K. Saxena, "Nanoparticle based drug delivery system: milestone for cancer therapy," Journal of Biomedical and Pharmaceutical Research, vol. 1, no. 2, pp. 1-6, 2012.

[20] G. Gregoriadis, "Engineering liposomes for drug delivery: progress and problems," Trends in Biotechnology, vol. 13, no. 12, pp. 527-537, 1995.

[21] F. Alexis, E. M. Pridgen, R. Langer, and O. C. Farokhzad, Nanoparticle Technologies for Cancer Therapy, Springer, Berlin, Germany, 2010.

[22] D. Peer, J. M. Karp, S. Hong, O. C. Farokhzad, R. Margalit, and R. Langer, "Nanocarriers as an emerging platform for cancer therapy," Nature Nanotechnology, vol. 2, no. 12, pp. 751-760, 2007.

[23] P. X. Hou, C. Liu, and H. M. Cheng, "Purification of carbon nanotubes," Carbon, vol. 46, no. 15, pp. 2003-2025, 2008.

[24] J. L. Zimmerman, R. K. Bradley, C. B. Huffman, R. H. Hauge, and J. L. Margrave, "Gas-phase purification of single-wall carbon nanotubes," Chemistry of Materials, vol. 12, no. 5, pp. 1361-1366, 2000.

[25] H. Hu, B. Zhao, M. E. Itkis, and R. C. Haddon, "Nitric acid purification of single-walled carbon nanotubes," The Journal of Physical Chemistry B, vol. 107, no. 50, pp. 13838-13842, 2003.

[26] S. Bandow, A. M. Rao, K. A. Williams, A. Thess, R. E. Smalley, and P. C. Eklund, "Purification of single-wall carbon nanotubes by microfiltration," The Journal of Physical Chemistry B, vol. 101, no. 44, pp. 8839-8842, 1997.

[27] A. P. Yu, E. Bekyarova, M. E. Itkis, D. Fakhrutdinov, R. Webster, and R. C. Haddon, "Application of centrifugation to the largescale purification of electric arc-produced single-walled carbon nanotubes," Journal of the American Chemical Society, vol. 128, no. 30, pp. 9902-9908, 2006.

[28] W. Huang, Y. Wang, G. H. Luo, and F. Wei, "99.9\% purity multi-walled carbon nanotubes by vacuum high-temperature annealing," Carbon, vol. 41, no. 13, pp. 2585-2590, 2003.

[29] P. X. Hou, S. Bai, Q. H. Yang, C. Liu, and H. M. Cheng, "Multistep purification of carbon nanotubes," Carbon, vol. 40, no. 1, pp. 81-85, 2002.

[30] N. Sinha and J. T. W. Yeow, "Carbon nanotubes for biomedical applications," IEEE Transactions on Nanobioscience, vol. 4, no. 2, pp. 180-195, 2005.

[31] B. Sitharaman, A. M. DeRosa, K. Greco, and S. Rajamani, "Recent patents on single-walled carbon nanotubes for biomedical imaging, drug delivery and tissue regeneration," Recent Patents on Biomedical Engineering, vol. 3, no. 2, pp. 86-94, 2010.

[32] M. Ohkohchi, Y. Ando, S. Bandow, and Y. Saito, "Formation of carbon nanotubes by evaporation of carbon rod containing scandium oxide," Japanese Journal of Applied Physics, vol. 32, no. 9, pp. L1248-L1251, 1993.

[33] S.-H. Jung, M.-R. Kim, S.-H. Jeong et al., "High-yield synthesis of multi-walled carbon nanotubes by arc discharge in liquid nitrogen," Applied Physics A: Materials Science \& Processing, vol. 76, no. 2, pp. 285-286, 2003.
[34] M. V. Antisari, R. Marazzi, and R. Krsmanovic, "Synthesis of multiwall carbon nanotubes by electric arc discharge in liquid environments," Carbon, vol. 41, no. 12, pp. 2393-2401, 2003.

[35] S. D. Wang, M. H. Chang, K. M. D. Lan, C. C. Wu, J. J. Cheng, and H. K. Chang, "Synthesis of carbon nanotubes by arc discharge in sodium chloride solution," Carbon, vol. 43, no. 8, pp. 1792-1795, 2005.

[36] K. Anazawa, K. Shimotani, C. Manabe, H. Watanabe, and M. Shimizu, "High-purity carbon nanotubes synthesis method by an arc discharging in magnetic field," Applied Physics Letters, vol. 81, no. 4, pp. 739-741, 2002.

[37] Y. Ando, X. Zhao, K. Hirahara, K. Suenaga, S. Bandow, and S. Iijima, "Mass production of single-wall carbon nanotubes by the arc plasma jet method," Chemical Physics Letters, vol. 323, no. 56, pp. 580-585, 2000.

[38] H. Cheng, C. Liu, H. Cang, M. Liu, Y. Fan, and G. Su, "Production of single-walled carbon nanotubes by a hydrogen arc discharge method," US Patent 6517800, 2003.

[39] S. Farhat, M. L. de la Chapelle, A. Loiseau et al., "Diameter control of single-walled carbon nanotubes using argon-helium mixture gases," The Journal of Chemical Physics, vol. 115, no. 14, pp. 6752-6759, 2001.

[40] H. Kajiura, Y. Liu, Y. Li et al., "Synthesis of single-walled carbon nanotubes by an arc-discharge method using selenium as a promoter," Carbon, vol. 49, no. 14, pp. 4792-4800, 2011.

[41] H. H. Kim and H. J. Kim, "Preparation of carbon nanotubes by DC arc discharge process under reduced pressure in an air atmosphere," Materials Science and Engineering B: Solid-State Materials for Advanced Technology, vol. 133, no. 1-3, pp. 241-244, 2006.

[42] S. B. Sinnott and R. Andrews, "Carbon nanotubes: synthesis, properties, and applications," Critical Reviews in Solid State and Materials Sciences, vol. 26, no. 3, pp. 145-249, 2001.

[43] H. Dai, "Carbon nanotubes: opportunities and challenges," Surface Science, vol. 500, no. 1-3, pp. 218-241, 2002.

[44] M. A. R. Mohd and J. Iqbal, "Production of carbon nanotubes by different routes-a review," Journal of Encapsulation and Adsorption Sciences, vol. 1, pp. 29-34, 2011.

[45] J. E. Herrera and D. E. Resasco, "Role of Co-W interaction in the selective growth of single-walled carbon nanotubes from $\mathrm{CO}$ disproportionation," The Journal of Physical Chemistry B, vol. 107, no. 16, pp. 3738-3746, 2003.

[46] J.-C. Charlier, H. Amara, and P. Lambin, "Catalytically assisted tip growth mechanism for single-wall carbon nanotubes," ACS Nano, vol. 1, no. 3, pp. 202-207, 2007.

[47] J. Gavillet, A. Loiseau, C. Journet, F. Willaime, F. Ducastelle, and J.-C. Charlier, "Root-growth mechanism for single-wall carbon nanotubes," Physical Review Letters, vol. 87, no. 27, part 1, Article ID 275504, 2001.

[48] P. Balbuena, J. Zhao, S. Huang, Y. Wang, N. Sakulchaicharoen, and D. E. Resasco, "Role of the catalyst in the growth of single-wall carbon nanotubes," Journal of Nanoscience and Nanotechnology, vol. 6, no. 5, pp. 1247-1258, 2006.

[49] S. Hofmann, M. Cantoro, S. Pisana et al., "Catalytic chemical vapor deposition of single-wall carbon nanotubes at low temperatures," Nano Letters, vol. 6, no. 6, pp. 1107-1112, 2006.

[50] M. Chen, C.-M. Chen, and C.-F. Chen, "Preparation of high yield multi-walled carbon nanotubes by microwave plasma chemical vapor deposition at low temperature," Journal of Materials Science, vol. 37, no. 17, pp. 3561-3567, 2002. 
[51] Y. C. Choi, D. J. Bae, Y. H. Lee et al., "Growth of carbon nanotubes by microwave plasma-enhanced chemical vapor deposition at low temperature," The Journal of Vacuum Science and Technology A: Vacuum, Surfaces and Films, vol. 18, no. 4, pp. 1864-1868, 2000.

[52] F. Huisken, R. Alexandrescu, A. Crunteanu et al., "Synthesis of carbon nanotubes by $\mathrm{CO}_{2}$-laser-assisted chemical vapour deposition," Infrared Physics \& Technology, vol. 44, no. 1, pp. 4350, 2003.

[53] W. J. Lackey, S. N. Bondi, R. W. Johnson, X. Wang, and Z. L. Wang, "Laser assisted chemical vapor deposition synthesis of carbon nanotubes and their characterization," Carbon, vol. 44, no. 8, pp. 1393-1403, 2006.

[54] A. A. Khodadadi and Y. Mortazavi, "Carbon nanotubes continuous synthesis process using iron floating catalysts and $\mathrm{MgO}$ particles for CVD of methane in a fluidized bed reactor," US Patent 8293204, 2012.

[55] H. Dai, "Nanotube growth and characterization," in Carbon Nanotubes, vol. 80 of Topics in Applied Physics, pp. 29-53, Springer, Berlin, Germany, 2001.

[56] T. Guo, P. Nikolaev, A. Thess, D. T. Colbert, and R. E. Smalley, "Catalytic growth of single-walled manotubes by laser vaporization," Chemical Physics Letters, vol. 243, no. 1-2, pp. 49-54, 1995.

[57] A. Szabo, C. Perri, A. Csato, G. Girodano, D. Vuono, and J. B. Nagy, "Synthesis methods of carbon nanotubes and related materials," Materials, vol. 3, no. 5, pp. 3092-3140, 2010.

[58] W. K. Maser, E. Munoz, A. M. Benito et al., "Production of high-density single-walled nanotube material by a simple laserablation method," Chemical Physics Letters, vol. 292, no. 4-6, pp. 587-593, 1998.

[59] M. Yudasaka, T. Ichihashi, T. Komatsu, and S. Iijima, "Singlewall carbon nanotubes formed by a single laser-beam pulse," Chemical Physics Letters, vol. 299, no. 1, pp. 91-96, 1999.

[60] H. Zhang, K. Chen, Y. He et al., "Formation and Raman spectroscopy of single wall carbon nanotubes synthesized by $\mathrm{CO}_{2}$ continuous laser vaporization," The Journal of Physics and Chemistry of Solids, vol. 62, no. 11, pp. 2007-2010, 2001.

[61] C. D. Scott, S. Arepalli, P. Nikolaev, and R. E. Smalley, "Growth mechanisms for single-wall carbon nanotubes in a laser-ablation process," Applied Physics A: Materials Science \& Processing, vol. 72, no. 5, pp. 573-580, 2001.

[62] W. K. Maser, E. Munoz, A. M. Benito et al., "Gas and pressure effects on the production of single-walled carbon nanotubes by laser ablation," Carbon, vol. 38, no. 10, pp. 1445-1451, 2000.

[63] R. L. Vander Wal, G. M. Berger, and T. M. Ticich, "Carbon nanotube synthesis in a flame using laser ablation for in situ catalyst generation," Applied Physics A: Materials Science \& Processing, vol. 77, no. 7, pp. 885-889, 2003.

[64] D. A. Gomez-Gualdron, J. C. Burgos, J. Yu, and P. B. Balbuena, "Carbon nanotubes: engineering biomedical applications," Progress in Molecular Biology and Translational Science, vol. 104, pp. 175-245, 2011.

[65] S. Ye, Y. Jiang, H. Zhang et al., "Modulation of apoptotic pathways of macrophages by surface-functionalized multi-walled carbon nanotubes," PLoS ONE, vol. 8, no. 6, article e65756, 2013.

[66] W. R. Chen, "Immunologically modified carbon nanotubes for cancer treatment," US Patent 20130172848, 2013.

[67] N. W. S. Kam, T. C. Jessop, P. A. Wender, and H. Dai, "Nanotube molecular transporters: internalization of carbon nanotube-protein conjugates into mammalian cells," Journal of the American Chemical Society, vol. 126, no. 22, pp. 6850-6851, 2004.
[68] K. A. Wepasnick, B. A. Smith, J. L. Bitter, and D. Howard Fairbrother, "Chemical and structural characterization of carbon nanotube surfaces," Analytical and Bioanalytical Chemistry, vol. 396, no. 3, pp. 1003-1014, 2010.

[69] C. Branca, F. Frusteri, V. Magazu, and A. Mangione, "Characterization of carbon nanotubes by TEM and infrared spectroscopy," The Journal of Physical Chemistry B, vol. 108, no. 11, pp. 3469-3473, 2004.

[70] P. Xu, D. Cui, B. Pan et al., "A facile strategy for covalent binding of nanoparticles onto carbon nanotubes," Applied Surface Science, vol. 254, no. 16, pp. 5236-5240, 2008.

[71] T. I. T. Okpalugo, P. Papakonstantinou, H. Murphy, J. McLaughlin, and N. M. D. Brown, "High resolution XPS characterization of chemical functionalised MWCNTs and SWCNTs," Carbon, vol. 43, no. 1, pp. 153-161, 2005.

[72] A. Peigney, C. Laurent, E. Flahaut, R. R. Bacsa, and A. Rousset, "Specific surface area of carbon nanotubes and bundles of carbon nanotubes," Carbon, vol. 39, no. 4, pp. 507-514, 2001.

[73] Y. Xing, N. Dementev, and E. Borguet, "Chemical labeling for quantitative characterization of surface chemistry," Current Opinion in Solid State and Materials Science, vol. 11, no. 5-6, pp. 86-91, 2007.

[74] J. P. Trigueiro, G. G. Silva, R. L. Lavall et al., "Purity evaluation of carbon nanotube materials by thermogravimetric, TEM, and SEM methods," Journal of Nanoscience and Nanotechnology, vol. 7, no. 10, pp. 3477-3486, 2007.

[75] L. S. K. Pang, J. D. Saxby, and S. P. Chatfield, "Thermogravimetric analysis of carbon nanotubes and nanoparticles," The Journal of Physical Chemistry, vol. 97, no. 27, pp. 6941-6942, 1993.

[76] J. H. Lehman, M. Terrones, E. Mansfield, K. E. Hurst, and V. Meunier, "Evaluating the characteristics of multiwall carbon nanotubes," Carbon, vol. 49, no. 8, pp. 2581-2602, 2011.

[77] M. S. Dresselhaus, A. Jorio, A. G. Souza Filho, and R. Saito, "Defect characterization in graphene and carbon nanotubes using Raman spectroscopy," Philosophical Transactions of the Royal Society A, vol. 368, no. 1932, pp. 5355-5377, 2010.

[78] Y. Xiao, X. Gao, O. Taratula et al., "Anti-HER2 IgY antibodyfunctionalized single-walled carbon nanotubes for detection and selective destruction of breast cancer cells," BMC Cancer, vol. 9, article 351, 2009.

[79] A. Bianco, K. Kostarelos, and M. Prato, "Applications of carbon nanotubes in drug delivery," Current Opinion in Chemical Biology, vol. 9, no. 6, pp. 674-679, 2005.

[80] K. Jiang, L. S. Schadler, R. W. Siegel, X. Zhang, H. Zhang, and $\mathrm{M}$. Terrones, "Protein immobilization on carbon nanotubes via a two-step process of diimide-activated amidation," Journal of Materials Chemistry, vol. 14, no. 1, pp. 37-39, 2004.

[81] K. A. Williams, P. T. M. Veenhuizen, B. G. V. de la Torre, R. Eritja, and C. Dekker, "Nanotechnology: carbon nanotubes with DNA recognition," Nature, vol. 420, no. 6917, pp. 761-762, 2002.

[82] N. W. S. Kam and H. Dai, "Single walled carbon nanotubes for transport and delivery of biological cargos," Physica Status Solidi $B$, vol. 243, no. 13, pp. 3561-3566, 2006.

[83] M. Holzinger, O. Vostrowsky, A. Hirsch et al., "Sidewall functionalization of carbon nanotubes," Angewandte Chemie, vol. 40, no. 21, pp. 4002-4005, 2001.

[84] A. Hirsch, "Functionalization of single-walled carbon nanotubes," Angewandte Chemie, vol. 41, no. 11, pp. 1853-1859, 2002.

[85] M. A. Hamon, J. Chen, H. Hu et al., "Dissolution of singlewalled carbon nanotubes," Advanced Materials, vol. 11, no. 10, pp. 834-840, 1999. 
[86] J. M. Tour, J. L. Hudson, C. R. Dyke, and J. J. Stephenson, "Functionalization of carbon nanotubes in acidic media," US Patent 20070280876, 2007.

[87] V. N. Khabashesku, M. L. Margrave, J. L. Stevens et al., "Side wall functionalization of single-wall carbon nanotubes through C$\mathrm{N}$ bending forming substitution of fluoronanotubes," US Patent 7452519, 2008.

[88] Z. Liu, X. Sun, N. Nakayama-Ratchford, and H. Dai, "Supramolecular chemistry on water-soluble carbon nanotubes for drug loading and delivery," ACS Nano, vol. 1, no. 1, pp. 50-56, 2007.

[89] A. Villaverde, Nanoparticles in Translational Science and Medicine, Academic Press, London, UK, 2011.

[90] T. Minko, "Soluble polymer conjugates for drug delivery," Drug Discovery Today: Technologies, vol. 2, no. 1, pp. 15-20, 2005.

[91] C. Y. Hu, Y. J. Xu, S. W. Duo, R. F. Zhang, and M. S. Li, "Noncovalent functionalization of carbon nanotubes with surfactants and polymers," Journal of the Chinese Chemical Society, vol. 56, no. 2, pp. 234-239, 2009.

[92] A. Star, J. F. Stoddart, D. Steuerman et al., "Preparation and properties of polymer-wrapped single-walled carbon nanotubes," Angewandte Chemie, vol. 40, no. 9, pp. 1721-1725, 2001.

[93] X. Zhao and J. K. Johnson, "Simulation of adsorption of DNA on carbon nanotubes," Journal of the American Chemical Society, vol. 129, no. 34, pp. 10438-10445, 2007.

[94] D. Pantarotto, J.-P. Briand, M. Prato, and A. Bianco, "Translocation of bioactive peptides across cell membranes by carbon nanotubes," Chemical Communications, no. 1, pp. 16-17, 2004.

[95] H. Kosuge, S. P. Sherlock, T. Kitagawa et al., "Near Infrared imaging and photothermal ablation of vascular inflammation using single-walled carbon nanotubes," Journal of the American Heart Association, vol. 1, no. 6, Article ID e002568, 2012.

[96] J. C. Bonner, J. K. Lee, B. C. Sayers et al., "Multi-walled carbon nanotubes induce COX-2 and iNOS expression via MAP Kinase-dependent and independent mechanisms in mouse RAW264.7 macrophages," Particle and Fibre Toxicology, vol. 9, article 14, 2012.

[97] B. Sitharaman and P. K. Avti, "Luminescent single-walled carbon nanotube-sensitized europium nanoprobes for cellular imaging," International Journal of Nanomedicine, vol. 7, pp. 1953-1964, 2012.

[98] Y. Lee and K. E. Geckeler, "Carbon nanotubes in the biological interphase: the relevance of noncovalence," Advanced Materials, vol. 22, no. 36, pp. 4076-4083, 2010.

[99] C. Fisher, A. E. Rider, Z. J. Han et al., "Applications and nanotoxicity of carbon nanotubes and graphene in biomedicine," Journal of Nanomaterials, vol. 2012, Article ID 315185, 19 pages, 2012.

[100] K. Kostarelos, A. Bianco, L. Lacerda et al., "Translocation mechanisms of chemically functionalised carbon nanotubes across plasma membranes," Biomaterials, vol. 33, no. 11, pp. 3334-3343, 2012.

[101] Q. Mu, D. L. Broughton, and B. Yan, "Endosomal leakage and nuclear translocation of multiwalled carbon nanotubes: developing a model for cell uptake," Nano Letters, vol. 9, no. 12, pp. 4370-4375, 2009.

[102] B. Alberts, A. Johnson, J. Lewis, M. Raff, K. Roberts, and P. Walter, "Transport into the cell from the plasma membrane: endocytosis," in Molecular Biology of the Cell, Garland Science, New York, NY, USA, 4th edition, 2002.
[103] R. Klingeler and R. B. Sim, Carbon Nanotubes for Biomedical Applications, Springer, Berlin, Germany, 2011.

[104] D. Zhao, D. Alizadeh, L. Zhang et al., "Carbon nanotubes enhance CpG uptake and potentiate antiglioma immunity," Clinical Cancer Research, vol. 17, no. 4, pp. 771-782, 2011.

[105] C. Iancu, L. Mocan, C. Bele et al., "Enhanced laser thermal ablation for the in vitro treatment of liver cancer by specific delivery of multiwalled carbon nanotubes functionalized with human serum albumin," International Journal of Nanomedicine, vol. 6, no. 1, pp. 129-141, 2011.

[106] S. Y. Madani, A. Tan, M. Dwek, and A. M. Seifalian, "Functionalization of single-walled carbon nanotubes and their binding to cancer cells," International Journal of Nanomedicine, vol. 7, pp. 905-914, 2012.

[107] S. Dhar, Z. Liu, J. Thomale, H. Dai, and S. J. Lippard, “Targeted single-wall carbon nanotube-mediated $\mathrm{Pt}(\mathrm{IV})$ prodrug delivery using folate as a homing device," Journal of the American Chemical Society, vol. 130, no. 34, pp. 11467-11476, 2008.

[108] F. Zhao, Y. Zhao, Y. Liu, X. Chang, C. Chen, and Y. Zhao, "Cellular uptake, intracellular trafficking, and cytotoxicity of nanomaterials," Small, vol. 7, no. 10, pp. 1322-1337, 2011.

[109] A. A. Kapralov, W. H. Feng, A. A. Amoscato et al., "Adsorption of surfactant lipids by single-walled carbon nanotubes in mouse lung upon pharyngeal aspiration: role in uptake by macrophages," ACS Nano, vol. 6, no. 5, pp. 4147-4156, 2012.

[110] Z. Liu, K. Chen, C. Davis et al., "Drug delivery with carbon nanotubes for in vivo cancer treatment," Cancer Research, vol. 68, no. 16, pp. 6652-6660, 2008.

[111] P. N. Yaron, B. D. Holt, P. A. Short, M. Lösche, M. F. Islam, and K. N. Dahl, "Single wall carbon nanotubes enter cells by endocytosis and not membrane penetration," Journal of Nanobiotechnology, vol. 9, article 45, 15 pages, 2011.

[112] K. Kostarelos, L. Lacerda, G. Pastorin et al., "Cellular uptake of functionalized carbon nanotubes is independent of functional group and cell type," Nature Nanotechnology, vol. 2, no. 2, pp. 108-113, 2007.

[113] P. A. Tran, L. Zhang, and T. J. Webster, "Carbon nanofibers and carbon nanotubes in regenerative medicine," Advanced Drug Delivery Reviews, vol. 61, no. 12, pp. 1097-1114, 2009.

[114] F. J. Rawson, C. L. Yeung, S. K. Jackson, and P. M. Mendes, "Tailoring 3D single-walled carbon nanotubes anchored to indium tin oxide for natural cellular uptake and intracellular sensing," Nano Letters, vol. 13, no. 1, pp. 1-8, 2013.

[115] O. Vittorio, V. Raffa, and A. Cuschieri, "Influence of purity and surface oxidation on cytotoxicity of multiwalled carbon nanotubes with human neuroblastoma cells," Nanomedicine: Nanotechnology, Biology, and Medicine, vol. 5, no. 4, pp. 424431, 2009.

[116] D. Xing, Z. Ou, B. Wu, F. Zhou, H. Wang, and Y. Tang, "Functional single-walled carbon nanotubes based on an integrin $\alpha_{v} \beta_{3}$ monoclonal antibody for highly efficient cancer cell targeting," Nanotechnology, vol. 20, no. 3, Article ID 105102, 7 pages, 2009.

[117] J. Ren, S. Shen, D. Wang et al., "The targeted delivery of anticancer drugs to brain glioma by PEGylated oxidized multiwalled carbon nanotubes modified with angiopep-2," Biomaterials, vol. 33, no. 11, pp. 3324-3333, 2012.

[118] Y.-J. Lu, K.-C. Wei, C.-C. Ma, S.-Y. Yang, and J.-P. Chen, "Dual targeted delivery of doxorubicin to cancer cells using folateconjugated magnetic multi-walled carbon nanotubes," Colloids and Surfaces B: Biointerfaces, vol. 89, no. 1, pp. 1-9, 2012. 
[119] C.-H. Wang, S.-H. Chiou, C.-P. Chou, Y.-C. Chen, Y.-J. Huang, and C.-A. Peng, "Photothermolysis of glioblastoma stem-like cells targeted by carbon nanotubes conjugated with CD133 monoclonal antibody," Nanomedicine: Nanotechnology, Biology, and Medicine, vol. 7, no. 1, pp. 69-79, 2011.

[120] B. Kateb, M. van Handel, L. Zhang, M. J. Bronikowski, H. Manohara, and B. Badie, "Internalization of MWCNTs by microglia: possible application in immunotherapy of brain tumors," NeuroImage, vol. 37, supplement 1, pp. S9-S17, 2007.

[121] S. M. Taghdisi, P. Lavaee, M. Ramezani, and K. Abnous, "Reversible targeting and controlled release delivery of daunorubicin to cancer cells by aptamer-wrapped carbon nanotubes," European Journal of Pharmaceutics and Biopharmaceutics, vol. 77, no. 2, pp. 200-206, 2011.

[122] X. Liu, H. Tao, K. Yang, S. Zhang, S.-T. Lee, and Z. Liu, "Optimization of surface chemistry on single-walled carbon nanotubes for in vivo photothermal ablation of tumors," Biomaterials, vol. 32, no. 1, pp. 144-151, 2011.

[123] B. Pan, D. Cui, P. Xu et al., "Synthesis and characterization of polyamidoamine dendrimer-coated multi-walled carbon nanotubes and their application in gene delivery systems," Nanotechnology, vol. 20, no. 12, Article ID 125101, pp. 1-9, 2009.

[124] K. Teker, "Bioconjugated carbon nanotubes for targeting cancer biomarkers," Materials Science and Engineering B: Solid-State Materials for Advanced Technology, vol. 153, no. 1-3, pp. 83-87, 2008.

[125] H. Chen, X. Ma, Z. Li et al., "Functionalization of singlewalled carbon nanotubes enables efficient intracellular delivery of siRNA targeting MDM2 to inhibit breast cancer cells growth," Biomedicine \& Pharmacotherapy, vol. 66, no. 5, pp. 334-338, 2012.

[126] B. Panchapakesan, S. Lu, K. Sivakumar, K. Teker, G. Cesarone, and E. Wickstrom, "Single-wall carbon nanotube nanobomb agents for killing breast cancer cells," Nanobiotechnology, vol. 1, no. 2, pp. 133-139, 2005.

[127] M. Abdolahad, Z. Sanaee, M. Janmaleki, S. Mohajerzadeh, M. Abdollahi, and M. Mehran, "Vertically aligned multiwallcarbon nanotubes to preferentially entrap highly metastatic cancerous cells," Carbon, vol. 50, no. 5, pp. 2010-2017, 2012.

[128] E. Heister, V. Neves, C. Tîlmaciu et al., "Triple functionalisation of single-walled carbon nanotubes with doxorubicin, a monoclonal antibody, and a fluorescent marker for targeted cancer therapy," Carbon, vol. 47, no. 9, pp. 2152-2160, 2009.

[129] L. Meng, Z. Ji, G. Lin et al., "Targeted therapy of SMMC-7721 liver cancer in vitro and in vivo with carbon nanotubes based drug delivery system," Journal of Colloid and Interface Science, vol. 365, no. 1, pp. 143-149, 2012.

[130] F. Yang, C. Jin, D. Yang et al., "Magnetic functionalised carbon nanotubes as drug vehicles for cancer lymph node metastasis treatment," European Journal of Cancer, vol. 47, no. 12, pp. 18731882, 2011.

[131] D. Cui, F. Tian, C. S. Ozkan, M. Wang, and H. Gao, "Effect of single wall carbon nanotubes on human HEK293 cells," Toxicology Letters, vol. 155, no. 1, pp. 73-85, 2005.

[132] G. M. do Nascimento, R. C. de Oliveira, N. A. Pradie et al., "Single-wall carbon nanotubes modified with organic dyes: synthesis, characterization and potential cytotoxic effects," Journal of Photochemistry and Photobiology A: Chemistry, vol. 211, no. 2-3, pp. 99-107, 2010.

[133] B. Wu, Z. Ou, and D. Xing, "Functional single-walled carbon nanotubes/chitosan conjugate for tumor cells targeting," in 8th
International Conference on Photonics and Imaging in Biology and Medicine (PIBM '09), vol. 7519 of Proceedings of SPIE, pp. 75190K1-75190K8, Wuhan, China, August 2009.

[134] R. Li, R. Wu, L. Zhao et al., "Folate and iron difunctionalized multiwall carbon nanotubes as dual-targeted drug nanocarrier to cancer cells," Carbon, vol. 49, no. 5, pp. 1797-1805, 2011.

[135] X. Zhang, X. Wang, Q. Lu, and C. Fu, "Influence of carbon nanotube scaffolds on human cervical carcinoma HeLa cell viability and focal adhesion kinase expression," Carbon, vol. 46, no. 3, pp. 453-460, 2008.

[136] X. Zhang, L. Meng, Q. Lu, Z. Fei, and P. J. Dyson, “Targeted delivery and controlled release of doxorubicin to cancer cells using modified single wall carbon nanotubes," Biomaterials, vol. 30, no. 30, pp. 6041-6047, 2009.

[137] L. Wang, J. Shi, H. Zhang et al., "Synergistic anticancer effect of RNAi and photothermal therapy mediated by functionalized single-walled carbon nanotubes," Biomaterials, vol. 34, no. 1, pp. 262-274, 2013.

[138] W. Geldenhuys, T. Mbimba, T. Bui, K. Harrison, and V. Sutariya, "Brain-targeted delivery of paclitaxel using glutathione-coated nanoparticles for brain cancers," Journal of Drug Targeting, vol. 19, no. 9, pp. 837-845, 2011.

[139] J. T. Huse and E. C. Holland, "Targeting brain cancer: advances in the molecular pathology of malignant glioma and medulloblastoma," Nature Reviews Cancer, vol. 10, no. 5, pp. 319-331, 2010.

[140] Y. Liang, Z. Zhong, Y. Huang et al., "Stem-like cancer cells are inducible by increasing genomic instability in cancer cells," The Journal of Biological Chemistry, vol. 285, no. 7, pp. 4931-4940, 2010.

[141] American Cancer Society, "What is Acute Lymphocytic Leukemia?" http://www.cancer.org/cancer/leukemiaacutelymphocyticallinadults/detailedguide/leukemia-acutelymphocytic-what-is-all.

[142] J. Ferlay, H. R. Shin, F. Bray, D. Forman, C. Mathers, and D. M. Parkin, "Estimates of worldwide burden of cancer in 2008: GLOBOCAN 2008," International Journal of Cancer, vol. 127, no. 12, pp. 2893-2917, 2010.

[143] T. Qin, Z. Yuan, R. Peng et al., "HER2-positive breast cancer patients receiving trastuzumab treatment obtain prognosis comparable with that of HER2-negative breast cancer patients," OncoTargets and Therapy, vol. 6, pp. 341-347, 2013.

[144] M. Donada, S. Bonin, R. Barbazza, D. Pettirosso, and G. stanta, "Management of stage II colon cancer-the use of molecular biomarkers for adjuvant therapy decision," $B M C$ Gastroenterology, vol. 13, article 36, 2013.

[145] C.-L. Teng, W.-L. Hwang, Y.-J. Chen, K.-H. Chang, and S.B. Cheng, "Sorafenib for hepatocellular carcinoma patients beyond Milan criteria after orthotopic liver transplantation: a case control study," World Journal of Surgical Oncology, vol. 10, article 41, 2012.

[146] C. P. Lin, C. R. Liu, C. N. Lee et al., "Targeting c-Myc as a novel approach for hepatocellular carcinoma," World Journal of Hepatology, vol. 2, no. 1, pp. 16-20, 2010.

[147] S. Kim, H. Nam, and D. Lee, "Exploring molecular links between lymph node invasion and cancer prognosis in human breast cancer," BMC Systems Biology, vol. 5, supplement 2, article S4, 14 pages, 2011.

[148] N. Mozzillo, C. Caracò, U. Marone et al., "Superficial and deep lymph node dissection for stage III cutaneous melanoma: clinical outcome and prognostic factors," World Journal of Surgical Oncology, vol. 11, article 36, 2013. 
[149] N. V. Vasudev, P. J. Selby, and R. E. Banks, "Renal cancer biomarkers: the promise of personalized care," BMC Medicine, vol. 10, article 112, 2012.

[150] J. Ferlay, D. M. Parkin, and E. Steliarova-Foucher, "Estimates of cancer incidence and mortality in Europe in 2008," European Journal of Cancer, vol. 46, no. 4, pp. 765-781, 2010.

[151] "Human Papillomavirus-Associated Cancers-United States, 2004-2008," American Journal of Transplantation, vol. 12, no. 7, pp. 1945-1949, 2012.

[152] A. Wu, Q. Zeng, T. H. Kang et al., "Innovative DNA vaccine for human papillomavirus (HPV)-associated head and neck cancer," Gene Therapy, vol. 18, no. 3, pp. 304-312, 2011.

[153] SEER Stat Fact Sheets: Prostate Cancer, http://seer.cancer.gov/ statfacts/html/prost.html.

[154] A. F. Neves, J. D. Dias-Oliveira, T. G. Araújo, K. Marangoni, and L. R. Goulart, "Prostate cancer antigen 3 (PCA3) RNA detection in blood and tissue samples for prostate cancer diagnosis," Clinical Chemistry and Laboratory Medicine, vol. 51, no. 4, pp. 881-887, 2013.

[155] W. Zhang, Z. Zhang, and Y. Zhang, "The application of carbon nanotubes in target drug delivery systems for cancer therapies," Nanoscale Research Letters, vol. 6, article 555, 2011.

[156] Y. Liu, Y. Zhao, B. Sun, and C. Chen, "Understanding the toxicity of carbon nanotubes," Accounts of Chemical Research, vol. 46, no. 3, pp. 702-713, 2013.

[157] Y. Rodriguez-Yañez, B. Muñoz, and A. Albores, "Mechanisms of toxicity by carbon nanotubes," Toxicology Mechanisms and Methods, vol. 23, no. 3, pp. 178-195, 2013.

[158] C.-W. Lam, J. T. James, R. McCluskey, and R. L. Hunter, "Pulmonary toxicity of single-wall carbon nanotubes in mice 7 and 90 days after intractracheal instillation," Toxicological Sciences, vol. 77, no. 1, pp. 126-134, 2004.

[159] L. Ma-Hock, V. Strauss, S. Treumann et al., "Comparative inhalation toxicity of multi-wall carbon nanotubes, graphene, graphite nanoplatelets and low surface carbon black," Particle and Fibre Toxicology, vol. 10, no. 1, article 23, 2013.

[160] D. B. Warheit, B. R. Laurence, K. L. Reed, D. H. Roach, G. A. M. Reynolds, and T. R. Webb, "Comparative pulmonary toxicity assessment of single-wall carbon nanotubes in rats," Toxicological Sciences, vol. 77, no. 1, pp. 117-125, 2004.

[161] J. Kanno, A. Takagi, A. Hirose et al., "Induction of mesothelioma in p53+/- mouse by intraperitoneal application of multi-wall carbon nanotube," The Journal of Toxicological Sciences, vol. 33, no. 1, pp. 105-116, 2008.

[162] S. Takanashi, K. Hara, K. Aoki et al., "Carcinogenicity evaluation for the application of carbon nanotubes as biomaterials in rasH2 mice," Scientific Reports, vol. 2, article 498, 2012.

[163] K. Donaldson, C. A. Poland, F. A. Murphy, M. MacFarlane, T. Chernova, and A. Schinwalda, "Pulmonary toxicity of carbon nanotubes and asbestos-similarities and differences," Advanced Drug Delivery Reviews, vol. 65, no. 15, pp. 2078-2068, 2013.

[164] N. A. Monteiro-Riviere, R. J. Nemanich, A. O. Inman, Y. Y. Wang, and J. E. Riviere, "Multi-walled carbon nanotube interactions with human epidermal keratinocytes," Toxicology Letters, vol. 155, no. 3, pp. 377-384, 2005.

[165] N. V. Pinto, N. F. de Andrade, D. S. Martinez et al., "Inflammatory and hyperalgesic effects of oxidized multi-walled carbon nanotubes in rats," Journal of Nanoscience and Nanotechnology, vol. 13, no. 8, pp. 5276-5282, 2013.
[166] F. Pons, G. Laverny, A. Casset et al., "Immunomodulatory properties of multi-walled carbon nanotubes in peripheral blood mononuclear cells from healthy subjects and allergic patients," Toxicology Letters, vol. 217, no. 2, pp. 91-101, 2013.

[167] B. N. Snyder-Talkington, D. Schwegler-Berry, V. Castranova, Y. Qian, and N. L. Guo, "Multi-walled carbon nanotubes induce human microvascular endothelial cellular effects in an alveolarcapillary co-culture with small airway epithelial cells," Particle and Fibre Toxicology, vol. 10, article 35, 2013.

[168] K. Shimizu, A. Uchiyama, M. Yamashita et al., "Biomembrane damage caused by exposure to multi walled carbon nanotubes," The Journal of Toxicological Sciences, vol. 38, no. 1, pp. 7-12, 2013.

[169] D. Liu, L. Wang, Z. Wang, and A. Cuschieri, "Different cellular response mechanisms contribute to the length-dependent cytotoxicity of multi-walled carbon nanotubes," Nanoscale Research Letters, vol. 7, no. 1, article 361, 2012.

[170] A. A. Shvedova, V. Castranova, E. R. Kisin et al., "Exposure to carbon nanotube material: assessment of nanotube cytotoxicity using human keratinocyte cells," Journal of Toxicology and Environmental Health A, vol. 66, no. 20, pp. 1909-1926, 2003.

[171] X. Tian, R. Li, X. Wang et al., "Surface charge and cellular processing of covalently functionalized multiwall carbon nanotubes determine pulmonary toxicity," ACS Nano, vol. 7, no. 3, pp. 2352-2368, 2013.

[172] S. Jain, R. P. Singh, M. Das, and V. Thakare, "Functionalization density dependent toxicity of oxidized multiwalled carbon nanotubes in a murine macrophage cell line," Chemical Research in Toxicology, vol. 25, no. 10, pp. 2127-2137, 2012.

[173] B. Wan, Z. X. Wang, Q. Y. Lv et al., "Single-walled carbon nanotubes and graphene oxides induce autophagosome accumulation and lysosome impairment in primarily cultured murine peritoneal macrophages," Toxicology Letters, vol. 221, no. 2, pp. 118-127, 2013.

[174] L. Campagnolo, M. Massimiani, G. Palmieri et al., "Biodistribution and toxicity of pegylated single wall carbon nanotubes in pregnant mice," Particle and Fibre Toxicology, vol. 10, no. 1, article 21, 2013. 

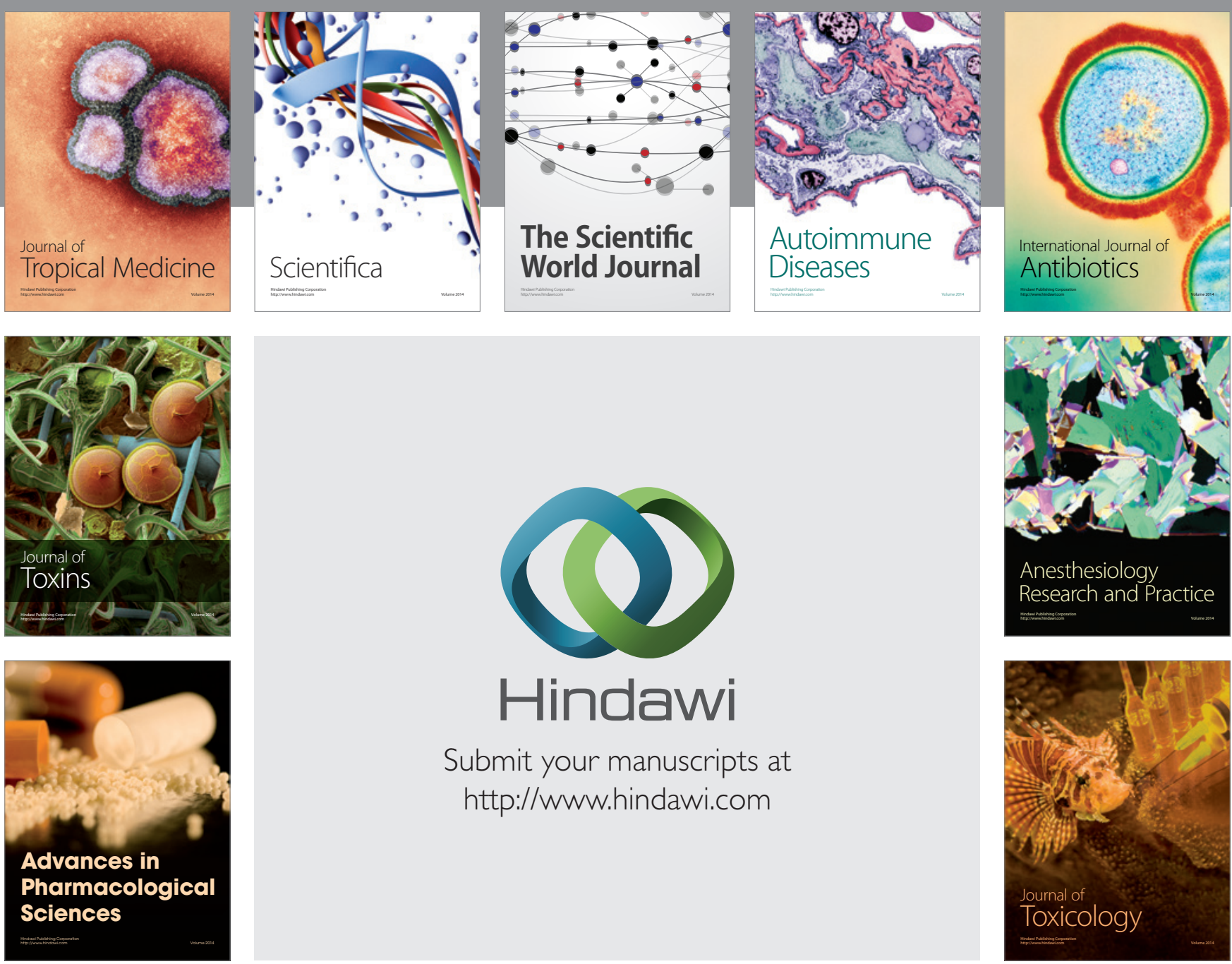

\section{Hindawi}

Submit your manuscripts at

http://www.hindawi.com
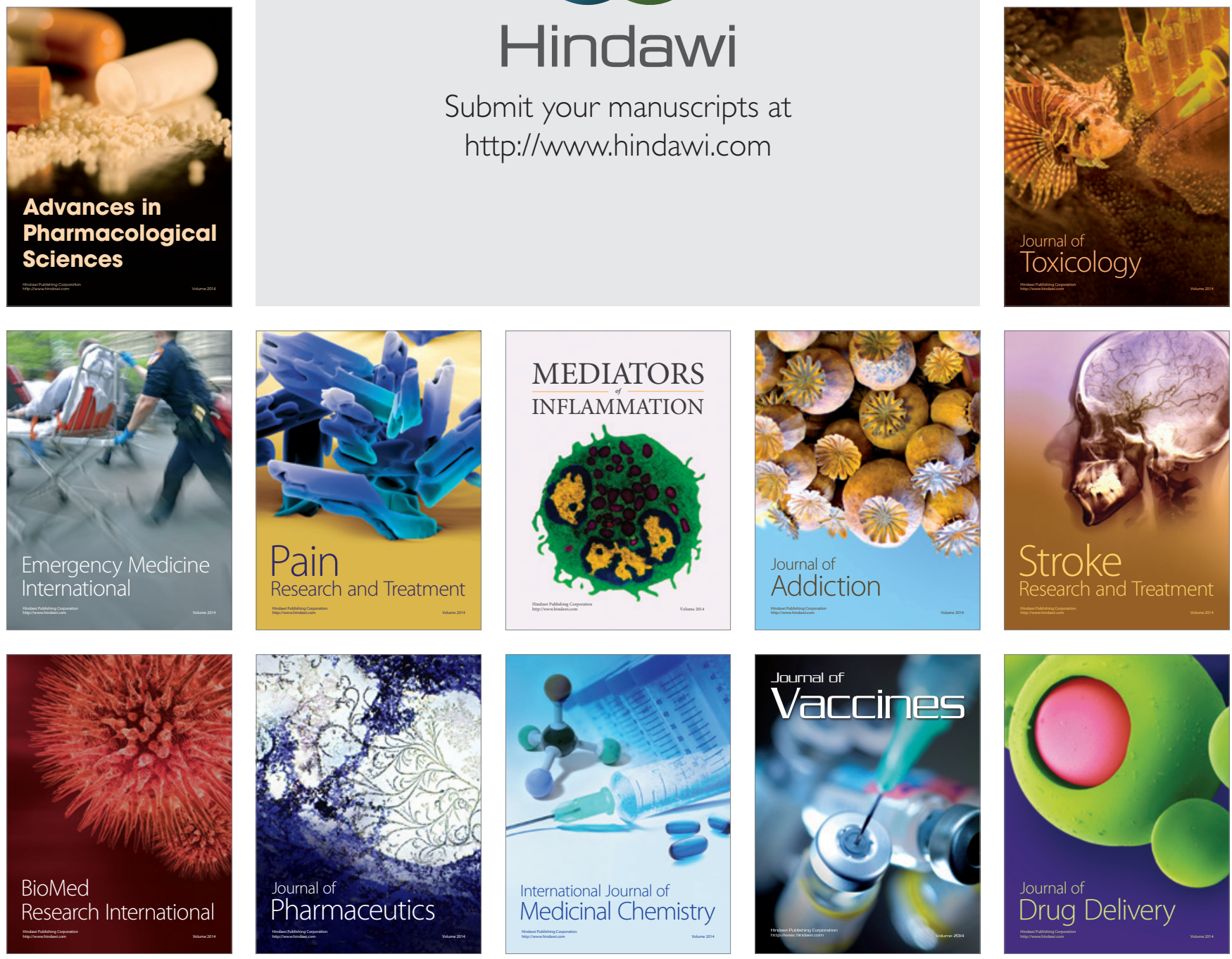